\title{
To Nap or Not to Nap? A Systematic Review Evaluating Napping Behavior in Athletes and the Impact on Various Measures of Athletic Performance
}

\author{
Michele Lastella (D) \\ Shona L Halson (D) $^{2}$ \\ Jacopo A Vitale $\mathbb{D}^{3}$ \\ Aamir R Memon (iD) 4 \\ Grace E Vincent (D)
}

'Appleton Institute for Behavioural Science, Central Queensland University, Adelaide, Australia; ${ }^{2}$ School of Behavioural and Health Sciences, Australian Catholic University, Brisbane, Australia; ${ }^{3}$ Laboratory of Movement and Sport Science, IRCCS Istituto Ortopedico Galeazzi, Milan, Italy; ${ }^{4}$ Institute of Physiotherapy \& Rehabilitation Sciences, Peoples University of Medical \& Health Sciences for Women, Nawabshah, Shaheed Benazirabad, Pakistan
Correspondence: Michele Lastella Appleton Institute for Behavioural Science, Central Queensland University, Adelaide, Australia

Tel +6I 4I3407956

Emailm.lastella@cqu.edu.au
Purpose: The objective of this systematic review was to 1) determine how studies evaluated napping behavior in athletes (frequency, duration, timing and measurement); 2) explore how napping impacted physical performance, cognitive performance, perceptual measures (eg, fatigue, muscle soreness, sleepiness and alertness), psychological state and night-time sleep in athletes.

Methods: Five bibliographic databases were searched from database inception to 11 August 2020. Observational and experimental studies comprising able-bodied athletes (mean age $\geq 12$ years), published in English, in peer-reviewed journal papers were included. The Downs and Black Quality Assessment Checklist was used for quality appraisal.

Results: Thirty-seven studies were identified of moderate quality. Most studies did not include consistent information regarding nap frequency, duration, and timing. Napping may be beneficial for a range of outcomes that benefit athletes (eg, physical and cognitive performance, perceptual measures, psychological state and night-time sleep). In addition, napping presents athletes with the opportunity to supplement their night-time sleep without compromising sleep quality.

Conclusion: Athletes may consider napping between 20 to $90 \mathrm{~min}$ in duration and between 13:00 and 16:00 hours. Finally, athletes should allow $30 \mathrm{~min}$ to reduce sleep inertia prior to training or competition to obtain better performance outcomes. Future studies should include comprehensive recordings of nap duration and quality, and consider using sleep over a 24 hour period (daytime naps and night-time sleep period), specifically using objective methods of sleep assessment (eg, polysomnography/actigraphy).

Keywords: athlete, health behavior, performance, physical health, psychological health, sleep, sports

\section{Introduction}

Napping is a ubiquitous behavior and an important public health tool to offset the adverse short- and long-term impacts of inadequate sleep. ${ }^{1}$ By definition, a nap is any sleep period with a duration of less than $50 \%$ of the average major sleep period of an individual. ${ }^{2}$ A nap is often referred to as a 'short sleep' which is distinct from, and considerably shorter than an individual's normal sleep episode. ${ }^{2,3}$ Naps may be further categorized into three main types: a) the prophylactic nap: a nap taken in anticipation of sleep loss; b) the replacement nap: a nap taken in response to sleep 
loss; and c) the appetitive nap: a nap taken for convenience and/or enjoyment. ${ }^{4}$ Another consideration absent within the sleep literature is the idea that athletes take naps as they are educated that napping may result in recovery and performance benefits. Napping during the day can increase the amount of sleep obtained in a 24-hour period and many athletes report including daytime napping in their training program. ${ }^{5,6}$ For example, Sargent et $\mathrm{al}^{6}$ demonstrated that more naps were taken on training days compared to rest days, and strategic napping during the day, as well as sleep hygiene practices (ie, healthy sleep practices) at night need to be considered. While several studies have investigated the impact of restricting or extending sleep on a number of outcomes of athletic performance (eg, sprint times, reaction time), ${ }^{7}$ there has been comparatively less focus on the impact of napping. ${ }^{8,9}$ It is possible that the lack of dedicated napping research in athletes may limit the ability of athletes, coaches and sports professionals to effectively implement strategic napping within their training programs.

Athletes are exposed to many stressors that impair sleep, including high training loads, competition demands, early morning training, travel and altitude exposure. ${ }^{9,10}$ As a result, athletes are often unable to obtain the recommended adult night-time sleep duration of 7-9 $\mathrm{h}$ per night. ${ }^{11}$ The majority of research examining athletes' sleep has focused on the impact of night-time sleep on performance and recovery. ${ }^{7,9}$ Yet, napping represents an opportunity to supplement the night-time sleep period, which may assist athletes in obtaining recommended sleep. Previous research on non-athletes has shown that napping can improve daytime sleepiness, mood and cognitive performance, ${ }^{12-14}$ with the magnitude of these effects comparable to other sleep restriction countermeasures (eg, caffeine, modafinil). ${ }^{3}$ However, despite the recent interest in napping in athletes, ${ }^{7,15}$ the impact of napping on athletes is yet to be systematically investigated. Therefore, the first aim of this study was to determine how studies evaluated napping behavior in athletes (frequency, duration, timing and measurement). The second aim of the study was to explore how napping impacted physical performance, cognitive performance, perceptual measures (eg, fatigue, muscle soreness, sleepiness and alertness), psychological state and night-time sleep in athletes. This review will provide key recommendations for practitioners and athletes, as well as directions for future research.

\section{Materials and Methods}

\section{Protocol Registration}

This systematic review followed the Preferred Reporting Items for Systematic Reviews and Meta Analyses (PRISMA) guidelines. ${ }^{16}$ The protocol for this review was registered in the PROSPERO database for systematic reviews (CRD42020208652).

\section{Search Strategy}

Five bibliographic databases (PsychINFO, PubMed, Scopus, SportDiscus, and Web of Science) were searched for relevant peer-reviewed journal papers from database inception to 11 August 2020. Articles were published in English and the search strategy combined napping terms ("nap", "daytime sleep", "siesta", "midday sleep", "midday nap", "afternoon nap", "daytime sleepiness") with athlete terms ("athlete/s", "elite athletes", "competitive athlete", "sport", "player"). In addition to the primary database searches, secondary searchers of reference lists of studies and citing articles meeting the inclusion criteria were carefully hand searched for potential inclusion of additional studies. The detailed search strategy is shown in Supplementary Material.

\section{Eligibility Criteria}

Studies were included according to the PEOS (Population, Exposure, Outcomes, Study design) format. The PEOS format was preferred over other reporting frameworks (eg, PICO) as the included studies were a mix of observational and interventional designs, which align more closely with the PEOS format. ${ }^{17}$

\section{Population}

Studies with able-bodied athletes, where the mean age of participants was $\geq 12$ years were included. Athletes between 12 and 18 years were included as young athletes as the International Olympic Committee underlies that athletes, especially young athletes should obtain sufficient sleep quantity and quality. ${ }^{18}$ Athlete was defined as someone who "engages in physical activity or sports with the primary goal of improving performance to bolster athletic excellence and/or achievement". 7,19,20 This did not include non-athletes, such as habitual exercisers, industrial or occupational athletes (eg, military, firefighters, ski patrol) and healthy sedentary or recreationally active volunteers. 


\section{Exposure}

A nap was defined as "a short sleep" which is distinct from and substantially shorter than an individual's normal sleep episode. ${ }^{2}$ In more quantifiable terms, it was defined as "any sleep period with a duration of less than $50 \%$ of the average main sleep period of an individual". ${ }^{21}$ Subjective (eg, self-report) and/or objective (eg, polysomnography, actigraphy) measures of sleep within the nap period were considered for inclusion.

\section{Outcome}

Outcomes included a) physical performance (eg, sprint times, time to exhaustion, grip strength, jump height), b) cognitive performance (eg, reaction time, levels of attention, levels of alertness), c) psychological state (eg, mood, well-being), and d) night-time sleep.

\section{Study Design}

Studies that were observational (eg, cross-sectional, casecontrol, cohort) or experimental (eg, randomized, nonrandomized trials, interventional trials) in nature were included.

\section{Other Criteria}

Full-text articles published in a peer-reviewed journal and in English language were included. Narrative reviews, systematic reviews, commentaries, viewpoints, editorials and errata documents were excluded. In addition, studies investigating napping behavior of Muslim (fasting) athletes during Ramadan were excluded as fasting may impact athlete's sleep.

\section{Study Selection}

All search results were imported into EndNote X7 software (Thomson Reuters, San Francisco, CA, USA). After removing duplicates, articles were independently screened by two reviewers (ML and ARM), based on title and abstract to determine their eligibility for inclusion. The full-texts of all included articles were then sourced and independently screened by two reviewers (ML and ARM) to ensure they met eligibility criteria. At all stages, conflicts were resolved through consensus or by involvement of a third reviewer (GEV).

\section{Data Extraction}

Using a standardized form, the following data were extracted independently by two reviewers (ML and ARM). Any discrepancies were identified and resolved through discussion or by involving a third reviewer
(GEV). The extracted data included i) publication details (eg, authors surname, publication year, country); ii) study design (eg, cross-sectional); iii) sample characteristics (eg, age and sex); iv) type of sport; v) napping measurement (eg, actigraphy, self-report); and vi) napping outcomes (eg, duration, frequency and context).

\section{Methodological Quality Assessment}

The methodological quality of included studies was assessed using the Downs and Black Quality Assessment Checklist, ${ }^{22}$ adjusted by the study design of included studies. Two reviewers (ARM and ML) conducted the assessment independently, with cases of uncertainty resolved by involving a third reviewer (GEV). For papers where one of the reviewers (ML) was a co-author, methodological quality assessment of studies was performed independently by two reviewers (ARM and GEV). Included studies were scored on 28 items for interventional, 20 for cohort and 16 for cross-sectional study designs. The overall quality scores were converted to a percentage value and rated as low (0-49\%), moderate (50-89\%) and high ( $\geq 90 \%){ }^{22,23}$

\section{Results}

\section{Study Identification and Selection}

The database searches yielded 2730 studies (PsychINFO: 73; PubMed: 122; Scopus: 1029; SportDiscus: 974; and Web of Science: 532). Secondary searches identified an additional relevant study. Duplicate records were removed $(\mathrm{n}=630)$ and the remaining 2101 records were assessed on the basis of title and abstract, with a further exclusion of 1992 studies. A total of 109 studies were eligible for full-text assessment. Of these, 72 studies were excluded because of the following reasons: participants were not athletes $(n=20)$, the study did not report napping data $(n=31)$, reviews $(n=7)$, no full-text $(n=9)$, nonscientific $(n=2)$, and Ramadan $(n=3)$. Thus, a total of 37 studies were included in the final review. ${ }^{5,6,8,24-57}$ The search process and number of studies retrieved at each stage are shown in Figure 1.

\section{Study Characteristics}

Thirty-seven studies were included in the systematic review, with detailed characteristics in Tables 1 and 2. Due to the amount of diversity and heterogeneity across studies, conducting a meta-analysis was not appropriate. The studies were published between 2009 and 2020 and consisted of 3489 participants. ${ }^{5,6,8,24-57}$ Both males and females were included 


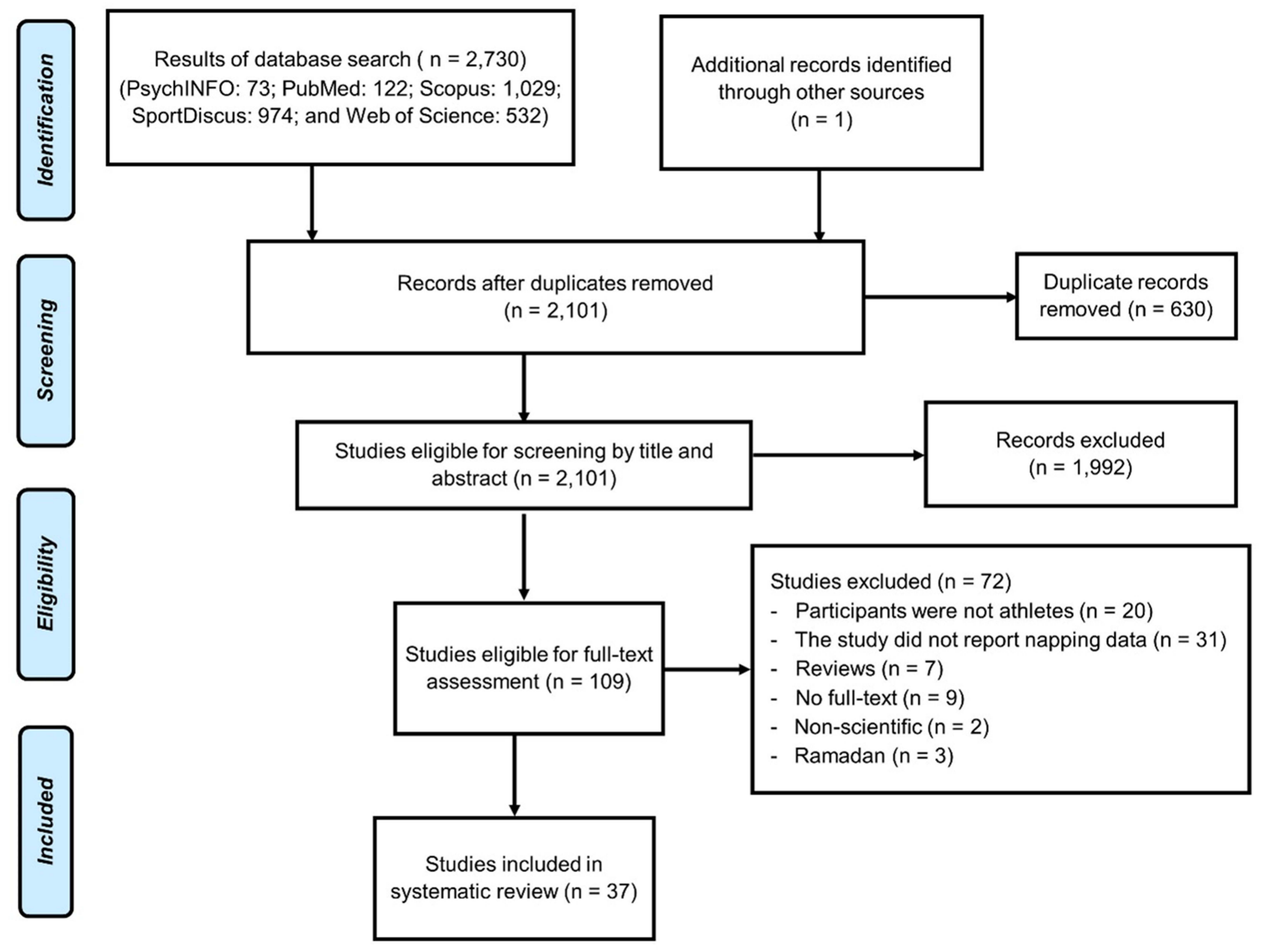

Figure I PRISMA flow diagram for the studies included in the review.

Notes: Adapted from Moher D, Liberati A, Tetzlaff J, Altman DG, PRISMA Group. Preferred reporting items for systematic reviews and meta-analyses: the PRISMA statement. PLoS Med. 2009;6(7):el000097. ${ }^{16}$ Creative Commons Attribution License.

in $35.1 \%(\mathrm{n}=13)$ of studies, $5,6,8,29,30,32,34-36,41,48,50,51 \quad 8.1 \%$ (n $=3$ ) of studies included females exclusively, ${ }^{37,38,57}$ and $48.6 \%$ (n $=18) \quad$ studies included males only. $^{24-26,31,33,37,40,42,43,45-47,49,52-56}$ Three studies $(8.1 \%) \mathrm{did}$ not report sex. ${ }^{27,28,44}$ The mean age of athletes was $23 \pm 4$ years. Study designs were as follows: cross-sectional $(\mathrm{n}=6),{ }^{25-30}$ longitudinal/cohort $(\mathrm{n}=14), 5,6,31-39,41,57,58$ randomized experimental $(\mathrm{n}=14),{ }^{24,42-49,52-56}$ and non-randomized experimental $(n=3) .{ }^{8,48,50}$ Athletes participated in 11 different sports (ie, karate, judo, netball, rowing, rugby, running, soccer, swimming, shooting marksmanship, track and field, and ultramarathon).

\section{Study Quality}

Overall, the risk of bias score ranged from $43.8 \%$ to $92.9 \%$, with $2.7 \%(\mathrm{n}=1)^{50}$ considered high quality, $91.9 \%(\mathrm{n}=34)^{5,6,8,24-27,29-47,49,51-57}$ considered moderate quality, and $5.4 \%(\mathrm{n}=2)^{28,59}$ considered low quality. The overall risk of bias for each study is presented in Figure 2A-C) and results for each item of the Downs and Black Checklist are provided in Supplementary material.

\section{Measuring Naps}

Overall, four main types of sleep assessments (eg, questionnaires, sleep diaries, actigraphy, and polysomnography) were used in the included studies. The most common form of sleep assessment was subjective, with ten $(27 \%)$ studies employing self-report questionnaires ${ }^{26-30,33,36,48,50,51}$ and seven $(18.9 \%)$ studies employing self-report sleep diaries. ${ }^{32,34,35,39,49,54,57}$ Thirteen (35.1\%) studies utilized wrist actigraphy as an objective form of sleep assessment, ${ }^{5,6,24,25,31,37,38,40-44,46}$ whereas six studies (16.2\%) used polysomnography, the gold standard in sleep assessment. ${ }^{8,47,52,53,55,56}$ One study 
(2.7\%) did not report any form of sleep assessment, however, sleep duration was controlled in a laboratory environment. ${ }^{45}$

\section{Napping Characteristics}

In total, $16(43.2 \%)$ studies reported napping characteristics of either frequency, duration and/or timing of naps taken by athletes. ${ }^{5,6,24-26,29,31,32,34-41}$ There was no consistency across studies for napping frequency (Table 1). Ten $(27 \%)$ studies reported the percentage of athletes who napped at least once throughout the data collection period. $5,6,25,26,29,34,36,39,41,60$ For example, Walsh et $\mathrm{al}^{41}$ showed that $33 \%$ of the participants (national and international level swimmers) reported napping at least once during a rest period, 75\% napped during a taper period, 92\% napped during a training period, and 75\% napped during the competition period. Five (13.5\%) studies reported the total amount of naps taken during the data collection period. ${ }^{6,24,31,37,40}$ For example, Caia et $\mathrm{al}^{31}$ reported a total of 16 naps were taken during 14 days of data collection with 8 naps taken during a 7-day preseason period and 8 naps taken during a 7-day competition period in professional Rugby League players. Overall, the percentage of participants that napped across studies ranged between $11 \%$ and $100 \%$ (Table 1).

The nap durations across all studies inclusive of training, rest, and competition phases ranged from 6 to $120 \mathrm{~min}$. Nap durations were similar between training ( $43 \pm 28 \mathrm{~min})$ and competition ( $44 \pm 24 \mathrm{~min}$ ) days. However, nap durations were considerably shorter on rest days $(6 \pm 10 \mathrm{~min}) .{ }^{41}$

Only three $(8.1 \%)$ studies reported nap timing, ${ }^{25,40,60}$ however reporting was inconsistent. For instance, Fullagar et $\mathrm{al}^{25}$ reported the exact nap start and end times (see Table 1), whereas Kolling et $\mathrm{al}^{35}$ reported the percentage of naps taken before 12:00, between 12:00 and 15:00 and between 15:00 and 18:00. Specifically, soccer players in the Fullagar et $\mathrm{al}^{25}$ study initiated naps at 14:44 $\pm 01: 03$ and ended naps at 16:12 $\pm 00: 59$. Rugby League players in the Thornton et al ${ }^{40}$ study were allocated specific times within the training schedule for napping such that naps were taken in the early morning (number of naps $<12: 00=71$; start 07:05 $\pm 00: 35$, end 07:52 $\pm 00: 18$ ) or afternoon (number of naps $<12: 00=85$; start 12:46 $\pm 00: 40$, end 13:40 $\pm 00: 47$ ).

In summary, the percentage of participants that napped across studies ranged between $11 \%$ and $100 \%$, with highest percentage of naps reported during training compared to rest days. While there was a large variability in the duration of naps (6-120 $\mathrm{min})$, nap durations on training and competition days were similar (43-44 min). Studies reporting data on the timing of naps were scarce with minimal consistency.

\section{Impact of Napping}

In total, 17 (45.9\%) studies examined at least one element of performance (eg, physical, cognitive), perceptual measures of fatigue or muscle soreness, perceived exertion and/or psychological state (eg, mood, stress). The following results section is divided into a) physical performance, b) cognitive performance, c) perceptual measures of fatigue, muscle soreness, sleepiness and alertness; d) psychological state; and e) night-time sleep.

\section{Physical Performance}

The impact of napping behavior on physical performance was assessed using various sport-specific measurement tests (see Table 2). Nine (24.7\%) studies found positive effects of napping on measures of physical performance, ${ }^{4-46,49,51,54,57}$ five (13.5\%) studies revealed no impact of napping ${ }^{50,51,53,56,57}$ and only two (5.4\%) studies revealed napping had a negative impact on performance. ${ }^{27,56}$ In the nine studies reporting positive effects of napping on measures of physical performance, participants were either a) well-rested or b) sleep restricted.

In well-rested athletes from both individual and team sports, Pelka et $\mathrm{al}^{50,51}$ examined the impact of napping (20 min nap) on maximum power using counter-movement jumps (ie, using a force platform) and maximum speed (ie, non-motorized treadmill) using two $6 \times 4$ second sprint sessions with 20 seconds breaks. While Pelka et $\mathrm{al}^{50}$ observed no differences in physical performance (speed or maximal power) between the napping and the control condition, improvements in average maximum speed, but not maximum power output were noted. In well-rested elite netballers, O'Donnell et $\mathrm{al}^{57}$ observed improvements in peak jump velocity (via counter-movement jumps) following short naps ( $<20 \mathrm{~min})$ compared to longer naps $(>20$ min) and the no nap condition. The authors found that the mean jump velocity was increased following longer naps compared to the no nap condition. However, no differences were observed between conditions for jump height. Further, Boukhris et $\mathrm{al}^{44}$ conducted a comprehensive study examining three different napping conditions (no nap, 40 min nap, 90 min nap) in amateur team sport athletes (soccer, rugby, handball). The findings revealed that maximal voluntary isometric contraction and total distance improved following both the $40 \mathrm{~min}$ and $90 \mathrm{~min}$ napping conditions compared to no nap. When exploring the differences between nap duration, the 90 min nap condition 


\begin{tabular}{|c|c|c|c|c|}
\hline 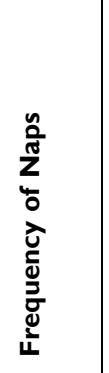 & 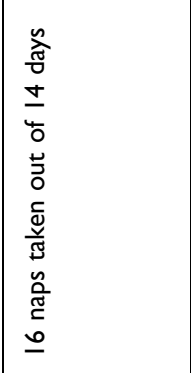 & $\frac{\alpha}{z}$ & $\frac{\alpha}{z}$ & $\stackrel{\alpha}{z}$ \\
\hline 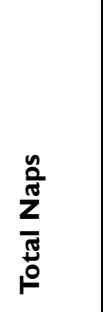 & 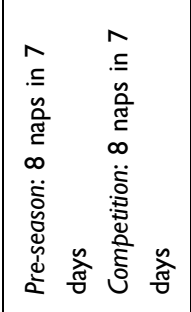 & $\frac{\alpha}{z}$ & 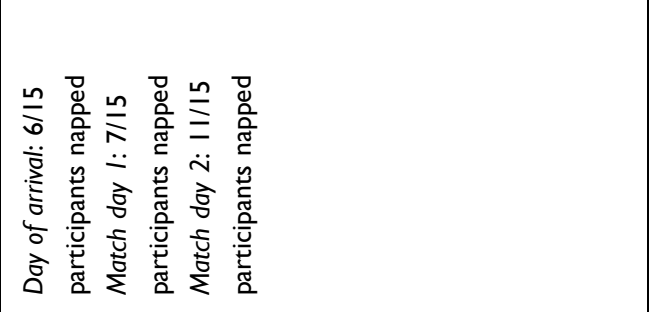 & 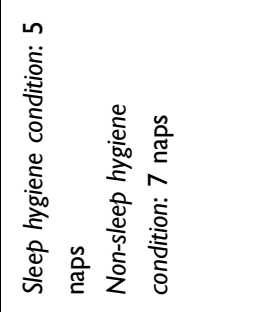 \\
\hline 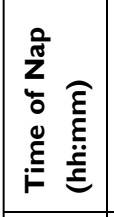 & $\frac{o}{z}$ & $\frac{\infty}{z}$ & 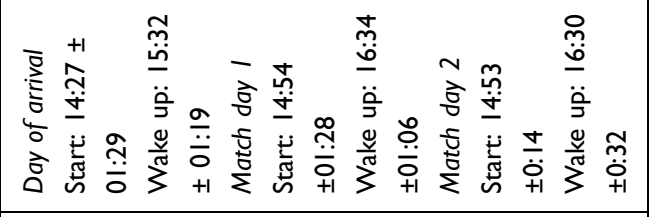 & $\frac{\infty}{z}$ \\
\hline 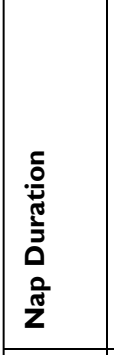 & 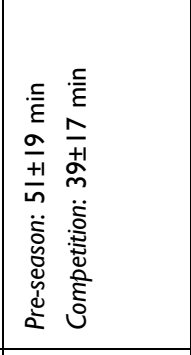 & 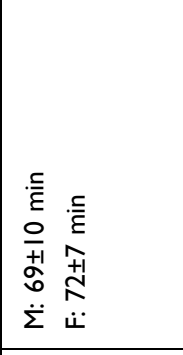 & 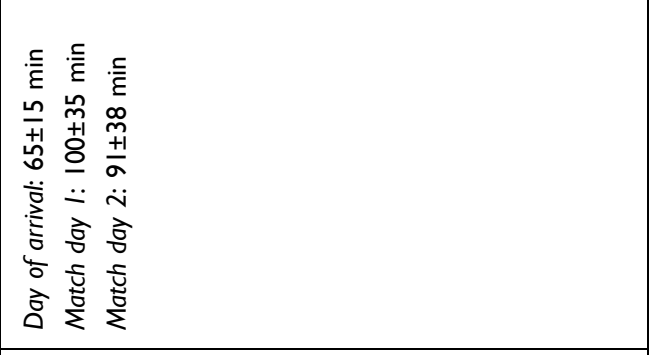 & 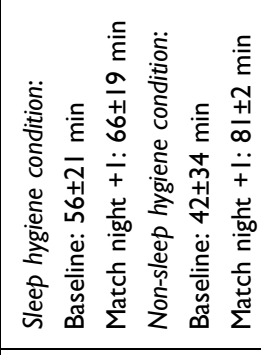 \\
\hline 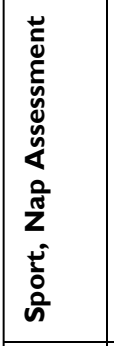 & 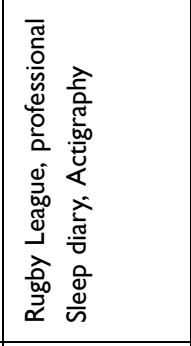 & 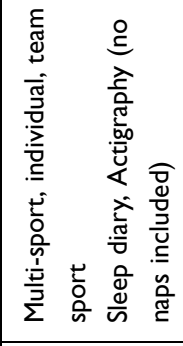 & 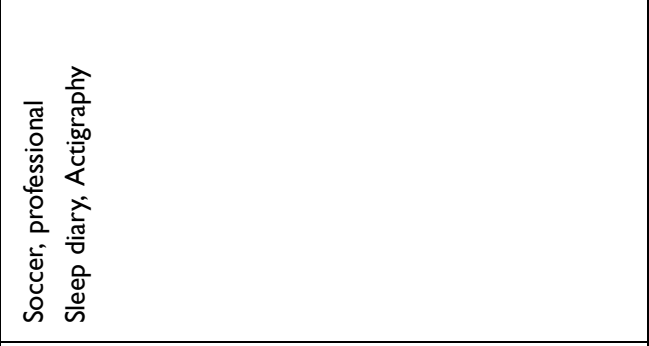 & 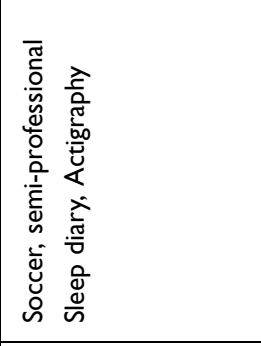 \\
\hline 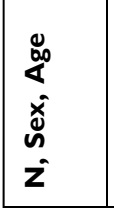 & 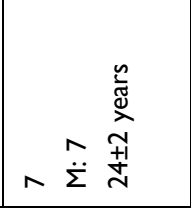 & 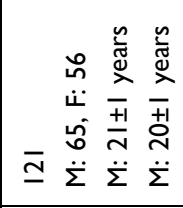 & 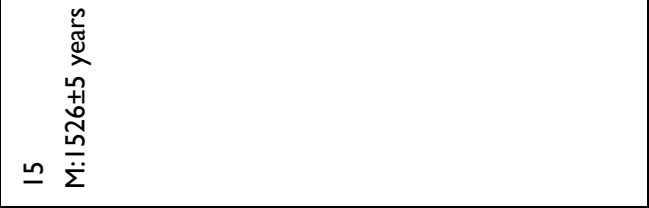 & 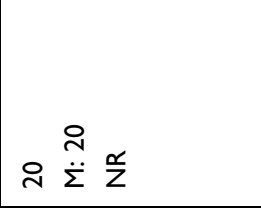 \\
\hline 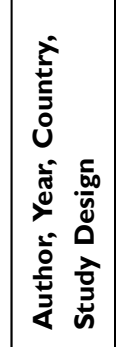 & 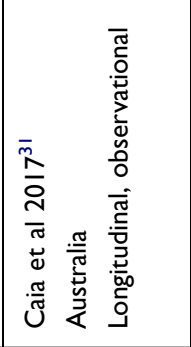 & 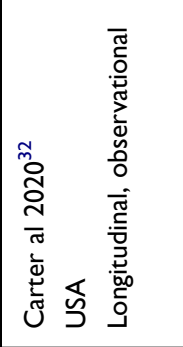 & 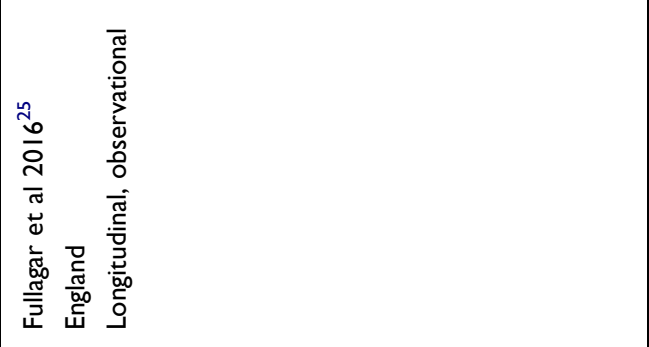 & 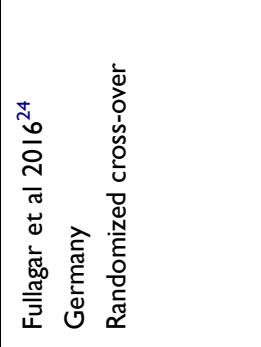 \\
\hline
\end{tabular}




\begin{tabular}{|c|c|c|c|c|c|}
\hline 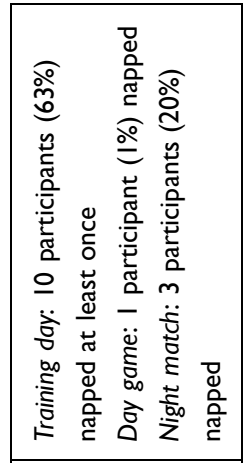 & & 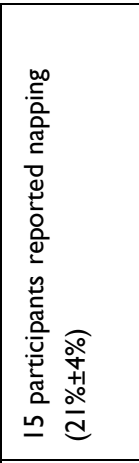 & 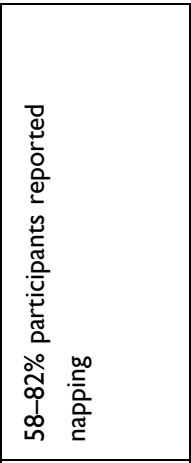 & 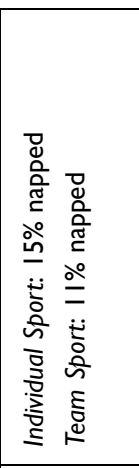 & 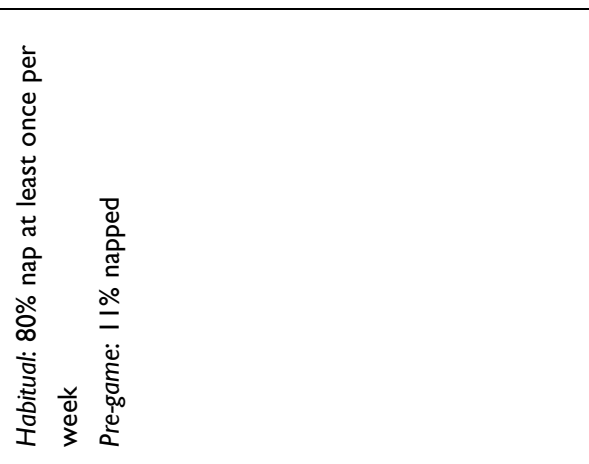 \\
\hline$\stackrel{\alpha}{z}$ & $\frac{\alpha}{z}$ & $\frac{\alpha}{z}$ & $\stackrel{\alpha}{z}$ & 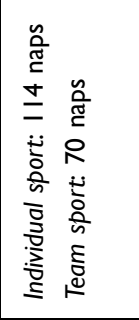 & \\
\hline$\frac{o}{z}$ & $\frac{\alpha}{z}$ & $\frac{\alpha}{z}$ & 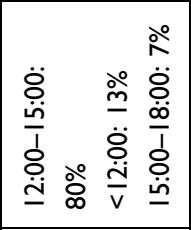 & $\frac{\infty}{z}$ & $\frac{\mathscr{o}}{z}$ \\
\hline 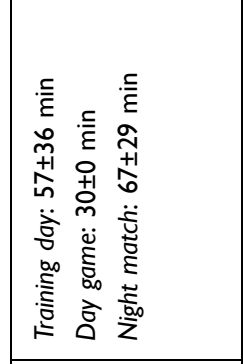 & 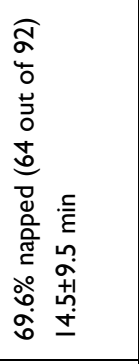 & 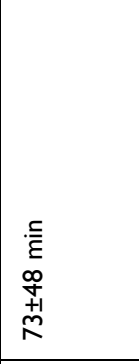 & 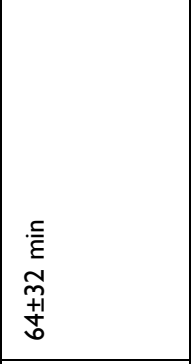 & 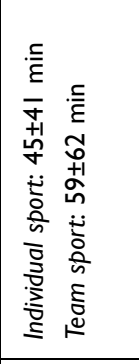 & 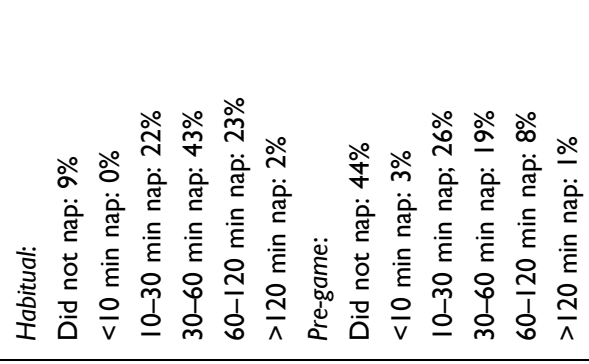 \\
\hline 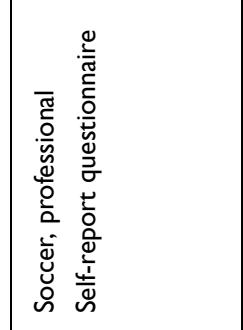 & 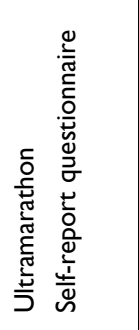 & 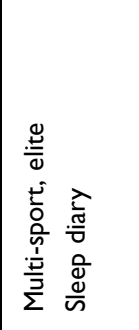 & 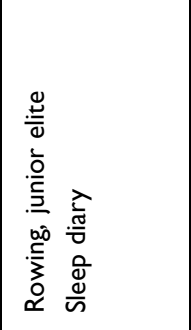 & 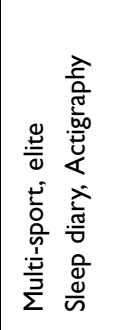 & 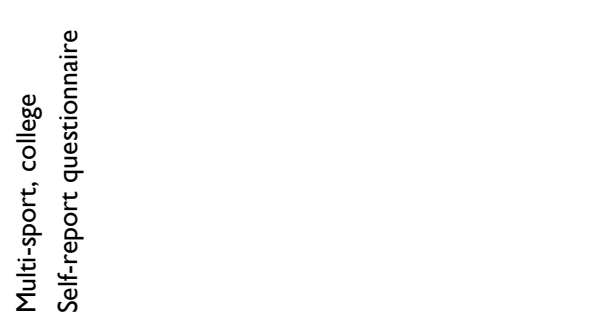 \\
\hline 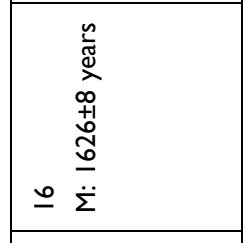 & 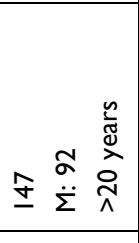 & 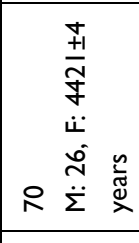 & 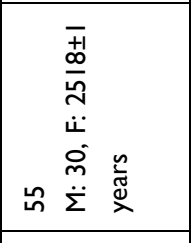 & 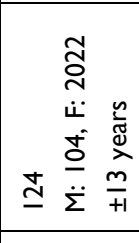 & 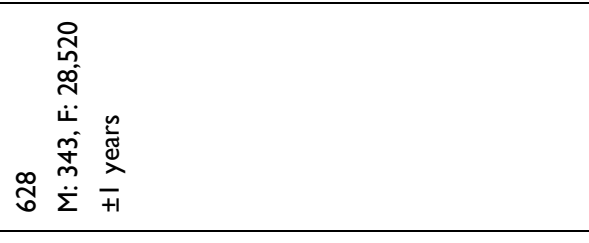 \\
\hline 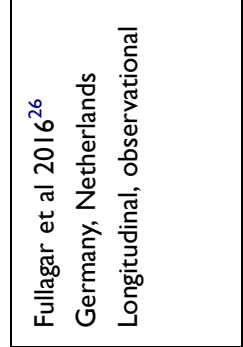 & 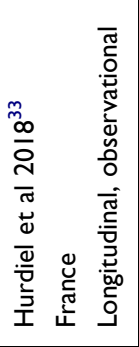 & 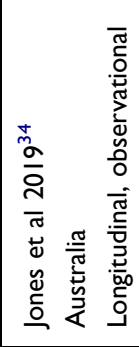 & 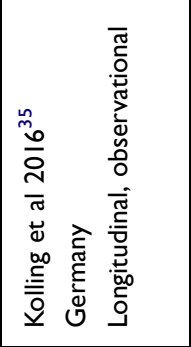 & 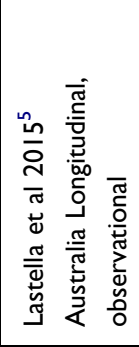 & 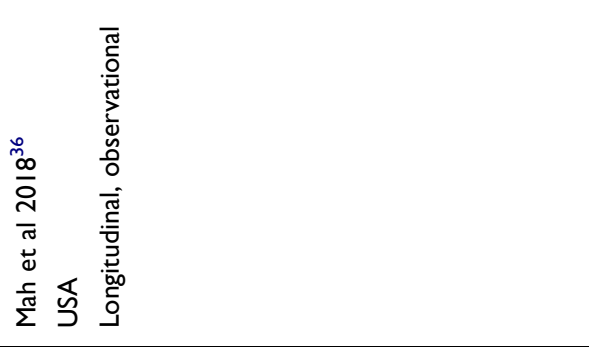 \\
\hline
\end{tabular}




\begin{tabular}{|c|c|c|c|c|c|c|}
\hline 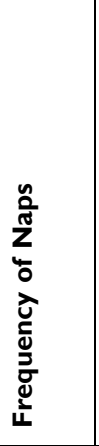 & 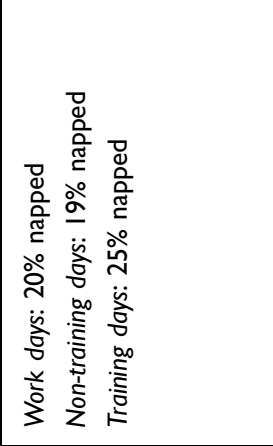 & & 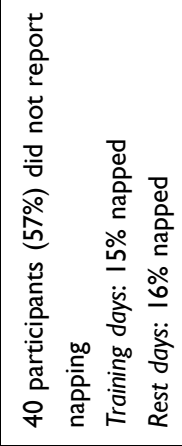 & 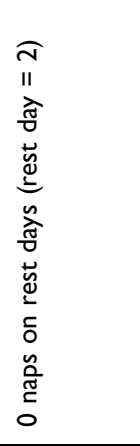 & 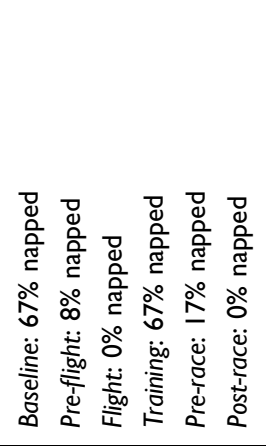 & 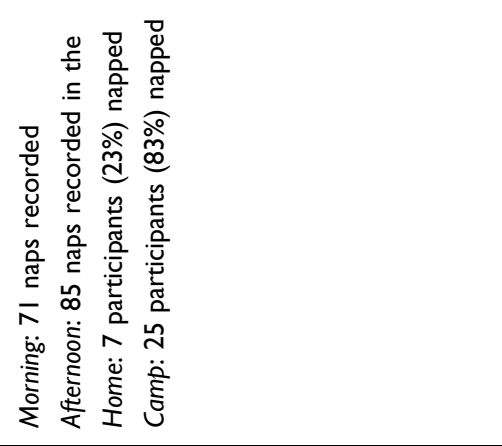 \\
\hline 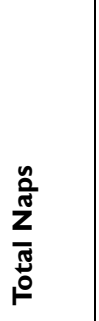 & $\stackrel{\alpha}{z}$ & 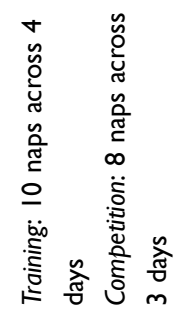 & 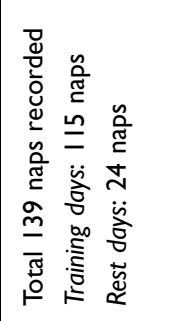 & 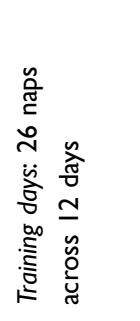 & 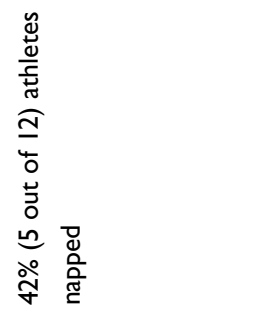 & \\
\hline 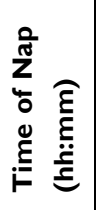 & 只 & $\stackrel{\alpha}{z}$ & $\stackrel{\alpha}{z}$ & $\frac{\alpha}{z}$ & $\frac{o}{z}$ & 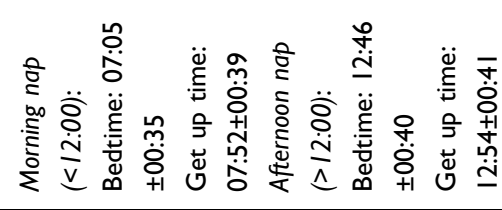 \\
\hline 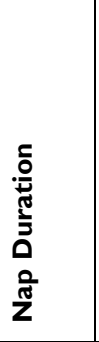 & 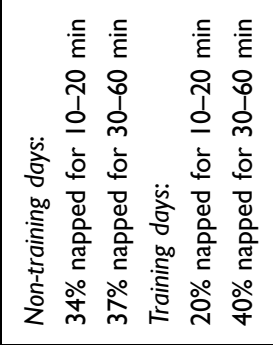 & 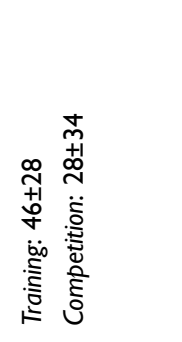 & $\begin{array}{l}\stackrel{c}{\varepsilon} \\
o \\
o+1 \\
+\frac{d}{d}\end{array}$ & 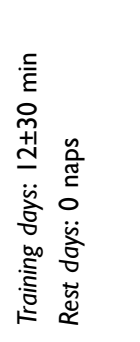 & 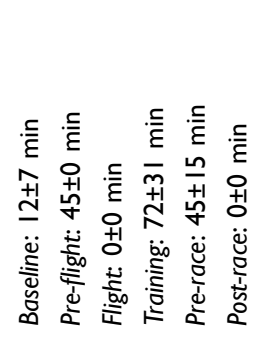 & 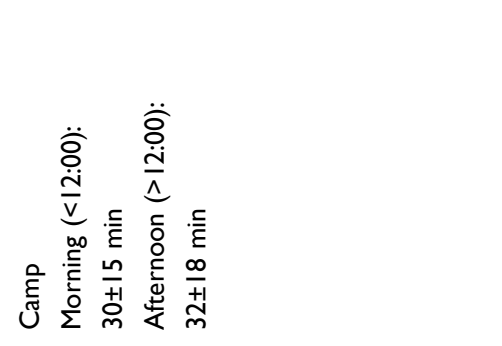 \\
\hline 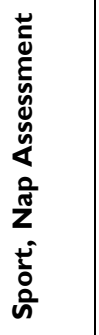 & 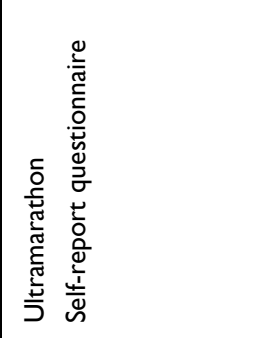 & 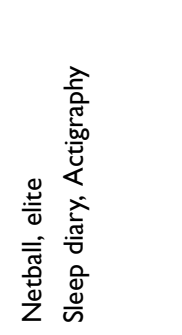 & 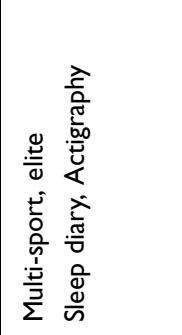 & 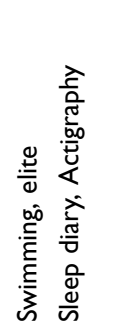 & 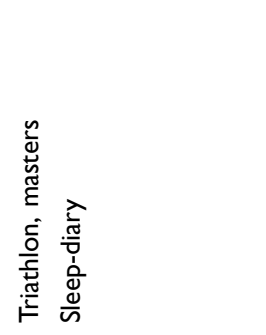 & 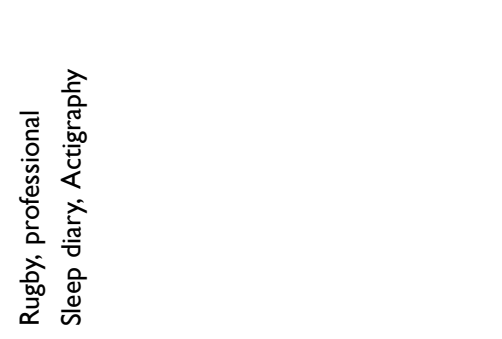 \\
\hline 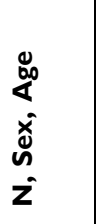 & 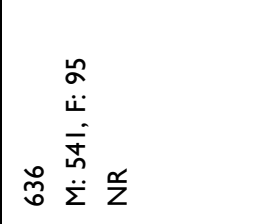 & 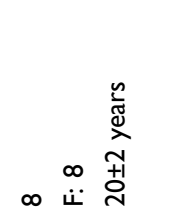 & 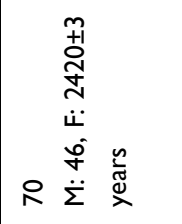 & ヘ & 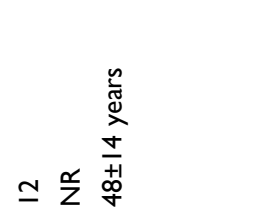 & 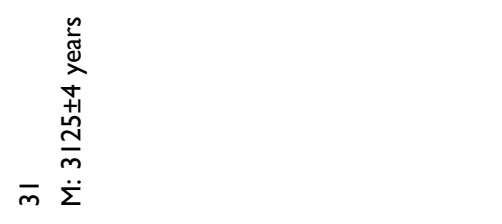 \\
\hline 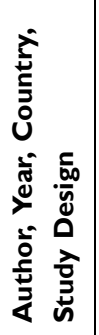 & 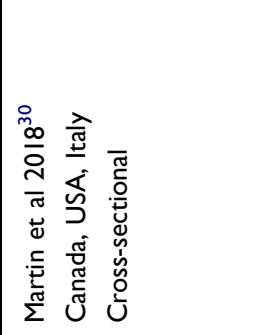 & 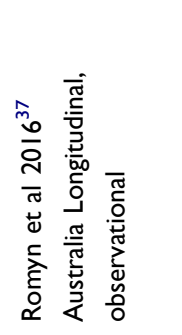 & 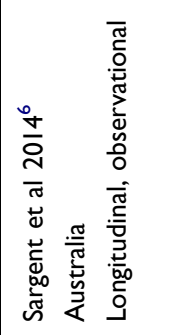 & 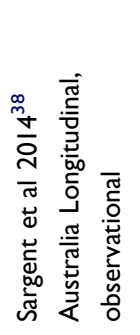 & 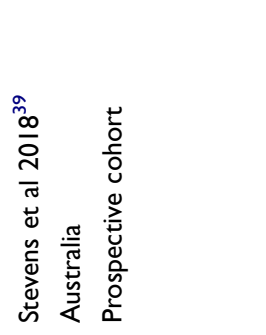 & 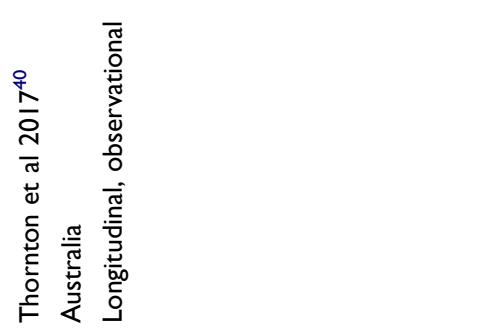 \\
\hline
\end{tabular}




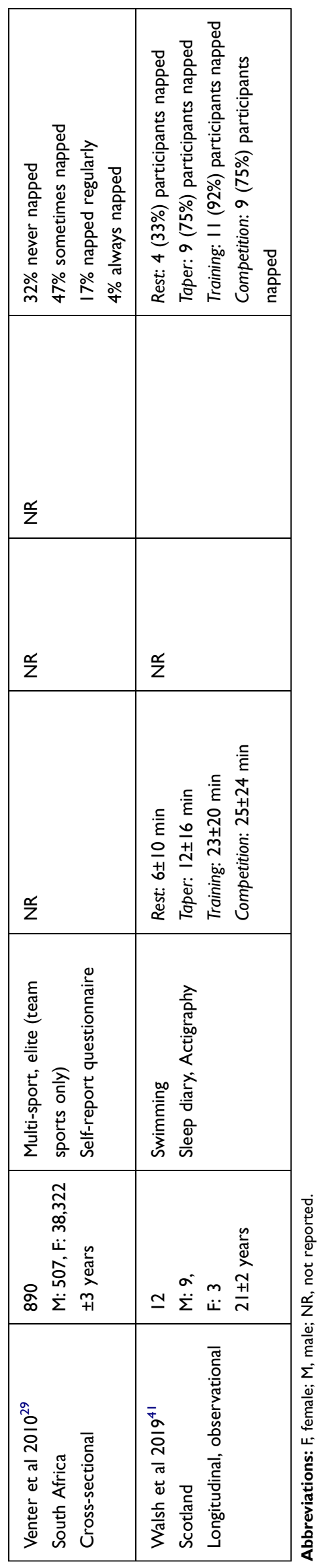

had greater benefits for maximal voluntary isometric contraction and total distance compared to the $40 \mathrm{~min}$ nap condition.

In sleep restricted athletes (range: 3.0-4.5 h), findings revealed consistent positive effects of napping on physical performance. ${ }^{42,45,46,49,54}$ Ajjimaporn et $\mathrm{al}^{42}$ and Brotherton et $\mathrm{al}^{45}$ both restricted sleep to $3 \mathrm{~h}$ of sleep per night in amateur soccer players and weightlifters, respectively. Ajjimaporn et $\mathrm{al}^{42}$ observed improvements in maximum isometric leg strength (via leg dynamometry) and mean power output following a 20 min nap. Although maximal power improved following a nap, this finding did not reach statistical significance. ${ }^{42}$ Brotherton et $\mathrm{al}^{45}$ examined weightlifting performance using grip strength, bench and leg press between three conditions (control $7.5 \mathrm{~h}$ sleep, 3.0 $\mathrm{h}$ sleep, $3.0 \mathrm{~h}$ sleep plus $60 \mathrm{~min}$ nap). Comparisons between the control condition and the $3 \mathrm{~h}$ sleep restriction accompanied with a 60 -min nap revealed no differences between the control and napping condition. However, the comparisons between $3 \mathrm{~h}$ sleep restriction and $3 \mathrm{~h}$ sleep restriction plus the 60 min nap condition revealed significant benefits for weightlifting performance, with grip strength, bench press (ie, power, peak velocity, force) and leg press (ie, power, distance) all higher following the 60 min nap compared to the no nap condition. Daaloul et $\mathrm{al}^{46}$ examined the impact of a 30 min nap after $4 \mathrm{~h}$ of sleep compared to $7 \mathrm{~h}$ of sleep on squat jumps, counter-movement jumps and a karate-specific test. While there was no initial impact of napping on squat jump and counter-movement jumps, following the fatigue induced by the karate-specific tests, the 30 min nap improved squat jump, countermovement jump performance and time to exhaustion compared to the no nap conditions. Further, Hammouda et $\mathrm{al}^{49}$ and Romdhani et al ${ }^{54}$ used the same napping conditions (no nap, 20 min nap, 90 min nap) following $4.5 \mathrm{~h}$ of sleep restriction to examine anaerobic capacity and power using the running anaerobic sprint test. ${ }^{61}$ Both studies reported significant improvements in power output and fatigue indices. It was also observed that the 90 min nap had greater effects on performance compared to the 20 min nap (Table 2). Blanchfield et $\mathrm{al}^{43}$ examined runners' time to exhaustion with and without a 90 min afternoon nap. While runners improved their time to exhaustion, previous night-time sleep duration predicted change in time to exhaustion such that naps had a greater influence on runners' time to exhaustion when they slept less than $7 \mathrm{~h}$ the previous night.

Four (10.8\%) studies reported napping during an ultramarathon. ${ }^{27,28,30,33}$ While Martin et $\mathrm{al}^{30}$ explored the 
Table 2 The Effects of Naps on Physical and Cognitive Performance, Perceptual Measures of Fatigue and Muscle Soreness, Sleepiness and Alertness, Psychological State, and Night-Time Sleep

\begin{tabular}{|c|c|c|}
\hline $\begin{array}{l}\text { Author, } \\
\text { Year }\end{array}$ & $\begin{array}{l}\text { Sleep Restriction, Nap Opportunity, } \\
\text { Performance Measures }\end{array}$ & $\begin{array}{l}\text { Effects of Napping (Physical Performance; Cognitive Performance; } \\
\text { Perceptual Measures of Fatigue and Muscle Soreness, Sleepiness } \\
\text { and Alertness; Psychological State; and Night-Time Sleep) }\end{array}$ \\
\hline $\begin{array}{l}\text { Ajjimaporn } \\
\text { et al } 2020^{42}\end{array}$ & $\begin{array}{l}\text { Sleep restriction: Control } 3 \text { h sleep } \\
\text { Nap opportunity: N20 } \\
\text { Performance measures: Running-based anaerobic } \\
\text { sprint test (RAST), Isometric dynamometer }\end{array}$ & $\begin{array}{l}\text { Physical performance: RAST in Control vs N20: } \downarrow \text { Maximum power, } \leftrightarrow \\
\text { Minimum power, } \uparrow \text { Fatigue, } \uparrow \text { Leg strength, } \uparrow \text { RPE } \\
\text { RAST in } 3 \mathrm{~h} \text { vs } 3 \mathrm{~h} \pm \text { N20: } \uparrow \text { Maximum power, } \uparrow \text { Minimum power, } \uparrow \text { Mean } \\
\text { power, } \leftrightarrow \text { Fatigue, } \uparrow \text { Leg strength, } \leftrightarrow \text { RPE } \\
\text { Cognitive performance: } \leftrightarrow \text { Auditory }\end{array}$ \\
\hline $\begin{array}{l}\text { Blanchfield } \\
\text { et al } 2018^{43}\end{array}$ & $\begin{array}{l}\text { Sleep restriction: No } \\
\text { Nap opportunity: No nap vs N20 } \\
\text { Performance measures: Motorized treadmill }\end{array}$ & $\begin{array}{l}\text { Physical performance: } \uparrow \text { RPE, } \uparrow \text { Time to exhaustion (only for participants that } \\
\text { slept }<7 \mathrm{~h} \text { ) } \\
\text { Perceptual measures of fatigue and muscle soreness, sleepiness and alertness: (ESS) } \\
\text { Sleepiness } \downarrow \text { immediately but returned to } \leftrightarrow 90 \text { min post nap } \\
\text { Psychological state: } \leftrightarrow \text { BRUMS }\end{array}$ \\
\hline $\begin{array}{l}\text { Boukhris } \\
\text { et al } 2020^{44}\end{array}$ & $\begin{array}{l}\text { Sleep restriction: No } \\
\text { Nap opportunity: No nap vs N40 vs N90 } \\
\text { Performance measures: Isometric dynamometer }\end{array}$ & $\begin{array}{l}\text { Physical performance: } \uparrow \mathrm{RPE}, \uparrow \mathrm{SMSRT}, \uparrow \text { Muscle contraction, } \uparrow \text { Higher distance, } \\
\uparrow \text { Total distance, } \uparrow \text { Perceived recovery, } \uparrow \text { Fatigue index, } \uparrow \text { DOMS, } \uparrow \text { DOMS } \\
\text { after N90 compared to N40, } \uparrow \text { all physical performances in N90 than N40 } \\
\text { Cognitive performance: } \uparrow \text { Attention, } \uparrow \text { attention in N90 than N40 } \\
\text { Perceptual measures of fatigue and muscle soreness, sleepiness and alertness: } \uparrow \\
\text { (SSS) Sleepiness, } \uparrow \text { (SSS) Sleepiness in N90 compared to N40 } \\
\text { Psychological state: } \uparrow \text { POMS, } \uparrow \text { tension, depression, fatigue, total mood score, } \\
\leftrightarrow \text { confusion, } \uparrow \text { perceived recovery, } \uparrow \text { perceived recovery in N90 than N40 }\end{array}$ \\
\hline $\begin{array}{l}\text { Brotherton } \\
\text { et al } 2019^{45}\end{array}$ & $\begin{array}{l}\text { Sleep restriction: Control } 3 \mathrm{~h} \text { for two nights } \\
\text { Nap opportunity: N60 ended } 3 \mathrm{~h} \text { before } \\
\text { performance } \\
\text { Performance measures: Force velocity platform }\end{array}$ & $\begin{array}{l}\text { Physical performance: Control vs Nap: } \leftrightarrow \text { Grip strength, } \leftrightarrow \text { Bench press } \\
\text { average power, } \uparrow \text { Bench press average force, } \uparrow \text { Bench Press peak velocity, } \leftrightarrow \\
\text { Time-to-peak velocity, } \leftrightarrow \text { Leg press average power, } \leftrightarrow \text { Leg press average } \\
\text { force, } \leftrightarrow \text { Leg press peak velocity, } \leftrightarrow \text { Leg press distance } \\
3 \mathrm{~h} \text { vs } 3 \mathrm{~h} \pm \text { N60: } \uparrow \text { Grip strength, } \uparrow \text { Bench press average power, } \uparrow \text { Bench } \\
\text { press average force, } \uparrow \text { Bench press peak velocity, } \uparrow \text { Time-to-peak velocity, } \uparrow \\
\text { Leg Press, } \uparrow \text { Leg Press average power, } \leftrightarrow \text { Leg press average force, } \leftrightarrow \text { Leg press } \\
\text { peak velocity, } \uparrow \text { Leg press distance } \\
\text { Perceptual measures of fatigue and muscle soreness, sleepiness and alertness: } \uparrow \\
\text { (SSS) Sleepiness, } \uparrow \text { (VAS) Alertness } \\
\text { Psychological state: Sleep Restricted vs Sleep Restricted with Nap: } \uparrow \text { POMS, } \\
\text { vigour, anger, calm, happiness, confusion, depression, fatigue, } \uparrow \text { Tiredness, } \leftrightarrow \\
\text { tension } \\
\text { Normal Sleep vs Sleep Restricted with Nap:: } \uparrow \text { POMS, vigour, calm, happiness, } \\
\text { confusion, depression, fatigue, } \uparrow \text { Tiredness, } \leftrightarrow \text { anger, tension, } \uparrow \text { Tiredness }\end{array}$ \\
\hline $\begin{array}{l}\text { Daaloul } \\
\text { et al } 2019^{46}\end{array}$ & $\begin{array}{l}\text { Sleep restriction: Control vs } 4 \text { h sleep vs } 4 \text { h sleep } \\
\text { with nap } \\
\text { Nap opportunity: No nap vs N30 } \\
\text { Performance measures: Optojump optical jump } \\
\text { system }\end{array}$ & $\begin{array}{l}\text { Physical performance: Control vs } 4 \text { h sleep } \pm \text { N30: } \leftrightarrow \text { Karate-specific test, } \leftrightarrow \\
\text { Squat jump, } \leftrightarrow \text { CMJ, } \uparrow \text { Time to exhaustion } \\
4 \text { h sleep vs } 4 \text { h sleep } \pm \text { N30: } \uparrow \text { Karate-specific test, } \uparrow \text { Squat jump, } \uparrow \text { CMJ, } \uparrow \\
\text { Time to exhaustion, } \uparrow \text { Fatigue } \\
\text { Cognitive performance: } \uparrow \text { Reaction time, } \uparrow \text { Mental rotation, } \uparrow \text { Lower body } \\
\text { reaction } \\
\text { Perceptual measures of fatigue and muscle soreness, sleepiness and alertness: } \uparrow \\
\text { (VAS) Alertness }\end{array}$ \\
\hline
\end{tabular}

(Continued) 
Table 2 (Continued).

\begin{tabular}{|c|c|c|}
\hline $\begin{array}{l}\text { Author, } \\
\text { Year }\end{array}$ & $\begin{array}{l}\text { Sleep Restriction, Nap Opportunity, } \\
\text { Performance Measures }\end{array}$ & $\begin{array}{l}\text { Effects of Napping (Physical Performance; Cognitive Performance; } \\
\text { Perceptual Measures of Fatigue and Muscle Soreness, Sleepiness } \\
\text { and Alertness; Psychological State; and Night-Time Sleep) }\end{array}$ \\
\hline $\begin{array}{l}\text { Davies et al } \\
2010^{47}\end{array}$ & $\begin{array}{l}\text { Sleep restriction: No } \\
\text { Nap opportunity: N90 } 60 \text { min after endurance } \\
\text { training vs N90 I } 20 \text { min after endurance training } \\
\text { Performance measures: Rowing ergometer, } \\
\text { Motorized treadmill }\end{array}$ & $\begin{array}{l}\text { Physical performance: } \uparrow \text { Readiness to perform for exercise } 2 \mathrm{~h} \text { post compared } \\
\text { to I h post } \\
\text { Perceptual measures of fatigue and muscle soreness, sleepiness and alertness: } \leftrightarrow \\
\text { (VAS) Alertness }\end{array}$ \\
\hline $\begin{array}{l}\text { Driller et al } \\
2016^{48}\end{array}$ & $\begin{array}{l}\text { Sleep restriction: No } \\
\text { Nap opportunity: } 45 \mathrm{~min} \text { in floatation device }\end{array}$ & $\begin{array}{l}\text { Physical performance: } \leftrightarrow \text { Muscle soreness } \\
\text { Psychological state: Multidimensional mood-state questionnaire }=\uparrow \text { Worn-out, } \\
\uparrow \text { At-ease, } \uparrow \text { Tense, } \uparrow \text { Fresh, } \uparrow \text { Exhausted }\end{array}$ \\
\hline $\begin{array}{l}\text { Hammouda } \\
\text { et al } 2018^{49}\end{array}$ & $\begin{array}{l}\text { Sleep restriction: } 4.5 \text { h sleep } \\
\text { Nap opportunity: No nap vs N20 vs N90 } \\
\text { Performance measures: Running-based anaerobic } \\
\text { sprint test (RAST) }\end{array}$ & $\begin{array}{l}\text { Physical performance: Both Napping Conditions: } \uparrow \text { RAST, } \uparrow \text { Maximum power, } \uparrow \\
\text { Minimum power, } \uparrow \text { Mean power, } \uparrow \text { Fatigue, } \uparrow \text { N90 than N20 }\end{array}$ \\
\hline $\begin{array}{l}\text { Knechtle } \\
\text { et al } 2012^{27}\end{array}$ & $\begin{array}{l}\text { Sleep restriction: Ultramarathon } \\
\text { Nap opportunity: Nap vs no nap } \\
\text { Performance measures: Race finish time }\end{array}$ & Physical performance: Nap $\downarrow$ race finish time \\
\hline $\begin{array}{l}\text { O’Donnell } \\
\text { et al } 2018^{57}\end{array}$ & $\begin{array}{l}\text { Sleep restriction: No } \\
\text { Nap opportunity: Short nap }(<20 \mathrm{~min}) \text { vs Long nap } \\
\text { (>20 min) } \\
\text { Performance measures: Linear transducer device }\end{array}$ & $\begin{array}{l}\text { Physical performance: Short nap } \uparrow \mathrm{CMJ}, \uparrow \text { Coach performance, } \leftrightarrow \text { Subjective } \\
\text { energy, } \leftrightarrow \text { Subjective player performance, } \leftrightarrow \text { Jump height }\end{array}$ \\
\hline $\begin{array}{l}\text { Pelka et al } \\
2017^{50}\end{array}$ & $\begin{array}{l}\text { Sleep restriction: No } \\
\text { Nap opportunity: N20 vs Systematic breathing } \\
\text { Performance measures: Non-motorized treadmill, } \\
\text { Contact platform }\end{array}$ & $\begin{array}{l}\text { Physical performance: } \leftrightarrow \text { Sprint, } \leftrightarrow \text { CMJ } \\
\text { Psychological state: } \leftrightarrow \text { Subjective rating }\end{array}$ \\
\hline $\begin{array}{l}\text { Pelka et al } \\
2017^{51}\end{array}$ & $\begin{array}{l}\text { Sleep restriction: No } \\
\text { Nap opportunity: N20 vs Yoga vs Systematic } \\
\text { breathing } \\
\text { Performance measures: Non-motorized treadmill }\end{array}$ & $\begin{array}{l}\text { Physical performance: } \uparrow \text { Speed, } \leftrightarrow \text { Maximum power output } \\
\text { Psychological state: } \leftrightarrow \text { Subjective recovery and stress }\end{array}$ \\
\hline $\begin{array}{l}\text { Petit et al } \\
2014^{53}\end{array}$ & $\begin{array}{l}\text { Sleep restriction: Control } 9 \mathrm{~h} \text { TIB } 5 \text { h phase advance } \\
\text { Nap opportunity: N20 } \\
\text { Performance measures: Cycle }\end{array}$ & $\begin{array}{l}\text { Physical performance: } \leftrightarrow \text { Wingate, } \leftrightarrow \text { Peak Power } \\
\text { Night-time sleep: Control condition and } 5 \text { h phase advance: } \downarrow \text { Sleep onset } \\
\text { latency, } \leftrightarrow \text { other sleep variables (eg, TST, SE, sleep stages) }\end{array}$ \\
\hline $\begin{array}{l}\text { Petit et al } \\
2018^{52}\end{array}$ & $\begin{array}{l}\text { Sleep restriction: Control } 9 \mathrm{~h} \text { TIB } 5 \text { h phase advance } \\
\text { Nap opportunity: N2I }\end{array}$ & $\begin{array}{l}\text { Cognitive performance: Control condition: } \uparrow \text { Vigilance, } \uparrow \text { Attentional } \\
\text { performance } \\
5 \text { h phase advance } \pm \text { nap: } \uparrow \text { Vigilance, } \uparrow \text { Attentional performance } \\
\text { Perceptual measures of fatigue and muscle soreness, sleepiness and alertness: } \\
\text { Control condition: } \uparrow \text { (VAS) Alertness } \\
5 \mathrm{~h} \text { phase advance: } \leftrightarrow \text { (VAS) Alertness }\end{array}$ \\
\hline $\begin{array}{l}\text { Poussel et al } \\
2015^{28}\end{array}$ & $\begin{array}{l}\text { Sleep restriction: Ultramarathon } \\
\text { Nap opportunity: Nap vs no nap } \\
\text { Performance measures: Race finish time }\end{array}$ & Physical performance: Napping $=\downarrow$ race finish time \\
\hline
\end{tabular}


Table 2 (Continued).

\begin{tabular}{|c|c|c|}
\hline $\begin{array}{l}\text { Author, } \\
\text { Year }\end{array}$ & $\begin{array}{l}\text { Sleep Restriction, Nap Opportunity, } \\
\text { Performance Measures }\end{array}$ & $\begin{array}{l}\text { Effects of Napping (Physical Performance; Cognitive Performance; } \\
\text { Perceptual Measures of Fatigue and Muscle Soreness, Sleepiness } \\
\text { and Alertness; Psychological State; and Night-Time Sleep) }\end{array}$ \\
\hline $\begin{array}{l}\text { Romdhani } \\
\text { et al } 2020^{54}\end{array}$ & $\begin{array}{l}\text { Sleep restriction: } 4.5 \text { h sleep } \\
\text { Nap opportunity: No nap vs } \mathrm{N} 20 \text { vs } \mathrm{N} 90 \\
\text { Performance measures: Running-based anaerobic } \\
\text { sprint test (RAST) }\end{array}$ & $\begin{array}{l}\text { Physical performance: N20 condition: RAST } \uparrow \text { Maximum power, } \leftrightarrow \text { Minimum } \\
\text { power, } \leftrightarrow \text { Mean power, } \uparrow \text { Fatigue } \\
\text { N90 condition: } \uparrow \text { Maximum power, } \uparrow \text { Minimum power, } \uparrow \text { Mean power, } \uparrow \\
\text { Fatigue, } \uparrow \text { RPE } \\
\text { Overall } \uparrow \text { N90 than N20 } \\
\text { Cognitive performance: } \uparrow \text { N20 Reaction time } \\
\text { Perceptual measures of fatigue and muscle soreness, sleepiness and alertness: } \uparrow \\
\text { (ESS) Sleepiness } \\
\text { Psychological state: } \uparrow \text { Wellness, } \uparrow \text { POMS } \\
\text { N90 vs N20: } \uparrow \text { Wellness, } \uparrow \text { POMS }\end{array}$ \\
\hline $\begin{array}{l}\text { Romyn et al } \\
2018^{55}\end{array}$ & $\begin{array}{l}\text { Sleep restriction: } 9 \text { h vs } 8 \mathrm{~h}+\mathrm{I} \text { h nap vs } 7 \mathrm{~h}+2 \mathrm{~h} \\
\text { nap } \\
\text { Nap opportunity: N60 vs NI } 20 \\
\text { Performance measures: Race finish time }\end{array}$ & Night-time sleep: $\leftrightarrow$ Sleep \\
\hline $\begin{array}{l}\text { Suppiah } \\
\text { et al } 2019^{56}\end{array}$ & $\begin{array}{l}\text { Sleep restriction: No } \\
\text { Performance measures: Timing gates }\end{array}$ & $\begin{array}{l}\text { Physical performance: } \leftrightarrow \text { Shooting performance, } \downarrow \text { Sprint performance } \\
\text { Perceptual measures of fatigue and muscle soreness, sleepiness and alertness: In } \\
\text { shooting athletes }=\uparrow \text { Sleepiness (in shooting athletes), } \downarrow \text { Alertness: In track } \\
\text { and field athletes }=\leftrightarrow \text { Sleepiness, } \leftrightarrow \text { Alertness }\end{array}$ \\
\hline $\begin{array}{l}\text { Thornton } \\
\text { et al } 2017^{40}\end{array}$ & Sleep restriction: No & Night-time sleep: $\uparrow$ Sleep, $\uparrow$ TIB, $\uparrow$ SE \\
\hline
\end{tabular}

Abbreviations: $\uparrow$, positive effect of napping; $\downarrow$, negative effect of napping; $\leftrightarrow$, no effect of napping; 5MSRT, 5 Metre Shuttle Run Test; BRUMS, Brunel Mood State Questionnaire; CMJ, counter movement jump; ESS, Epworth Sleepiness Scale; N before any number indicates mins of nap (eg, N20 = 20 min nap); POMS, Profile of Mood State Questionnaire; RAST, Running-based Anaerobic Sprint Test; RPE, rating of perceived exertion; SE, sleep efficacy; SSS, Stanford Sleepiness Scale; TIB, time in bed; TST, total sleep time; VAS, Visual Analogue Scale.

sleep habits of ultramarathon runners during training, the authors did not examine the impact of napping during an ultramarathon (Table 1). In addition, Hurdiel et $\mathrm{al}^{33}$ reported that $70 \%$ of runners reported napping during the ultramarathon obtaining an average of $23 \pm 22 \mathrm{~min}$ of sleep. The authors found that the race finish time was positively related to the amount of sleep obtained during the ultramarathon. In contrast, Knechtle et $\mathrm{al}^{27}$ and Poussel et $\mathrm{al}^{28}$ observed that runners that napped during an ultramarathon finished the race significantly slower than those who did not nap. Knechtle et $\mathrm{al}^{27}$ found that a total of $57 \%$ runners napped during the ultramarathon with nap durations ranging from 30 to $175 \mathrm{~min}$, while Poussel et $\mathrm{al}^{28}$ revealed that $28 \%$ took at least one nap with the majority of participants napping between 15 and $30 \mathrm{~min}$.

Only two (5.4\%) studies reported that napping negatively affected physical performance. ${ }^{27,56}$ While Suppiah et $\mathrm{al}^{56}$ demonstrated that $20 \mathrm{~m}$ sprint times were slower following a nap compared to no nap, other measures of performance in this study (other sprint distance times and shooting performance) were not different between the nap and no nap condition. Further, the study by Knechtle et $\mathrm{al}^{27}$ was conducted during a continuous ultra-cycling race $(\sim 24$ hours in duration) which examined the finish time and found that stopping to nap during the race logically delays the finish time of competitors who napped.

In summary, the physical performance benefits of napping are greater in sleep restricted athletes compared to well-rested athletes. While shorter naps ( $\sim 20 \mathrm{~min})$ show physical performance benefits, longer naps ( $\sim 90 \mathrm{~min})$ were likely to yield more benefits to physical performance.

\section{Cognitive Performance}

Five (13.5\%) studies examined the impact of cognitive performance following napping. Four of the five studies demonstrated a positive influence of napping on cognitive performance. ${ }^{44,46,52,54}$ Boukhris et $\mathrm{al}^{44}$ examined three conditions (no nap, $40 \mathrm{~min}$ nap, $90 \mathrm{~min}$ nap) without sleep restriction. While the authors observed that both nap conditions improved attention using the digit 


\section{A. Cross-sectional design}

Study

Fullagar et al. $2016^{26}$ Fullagar et al. $2016^{25}$ Knechtle et al. $2012^{27}$ Martin et al. $2018^{30}$ Poussel et al. $2015^{28}$ Venter et al. $2010^{29}$

Study

Caia et al. $2017^{31}$ Carter et al. $2020^{32}$ Hurdiel et al. $2018^{33}$ Jones et al. $2019^{34}$ Kölling et al. $2016^{35}$ Lastella et al. $2015^{5}$ Mah et al. $2018^{36}$ O'Donnell et al. $2018^{57}$ Romyn et al. $2016^{37}$ Sargent et al. $2014^{6}$ Sargent et al. $2014^{38}$ Stevens et al. $2018^{39}$ Thornton et al. $2017^{40}$ Walsh et al. $2019^{41}$

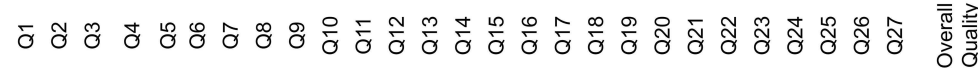

\section{B. Longitudinal design}

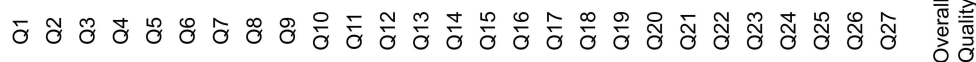

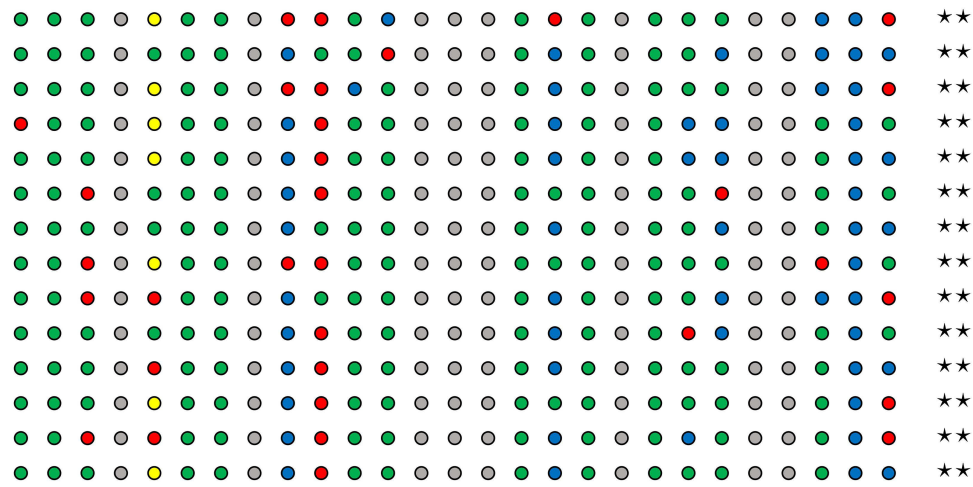

\section{Experimental design}

Study

Ajjimaporn et al. $2020^{42}$
Blanchfield et al. $2018^{43}$
Boukhris et al. $2020^{44}$
Brotherton et al. $2019^{45}$
Daaloul et al. $2019^{46}$
Davies et al. $2010^{47}$
Driller et al. $2016^{48}$
Fullagar et al. $2016^{24}$
Gupta et al. $2020^{8}$
Hammouda et al. $2018^{49}$
Pelka et al. $2017^{50}$
Pelka et al. $2017^{51}$
Petit et al. $2014^{53}$
Petit et al. $2018^{52}$
Romdhani et al. $2020^{54}$
Romyn et al. $2018^{55}$
Suppiah et al. $2018^{56}$

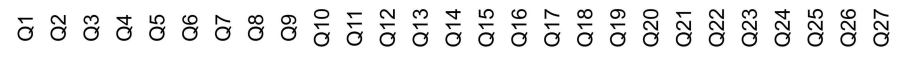

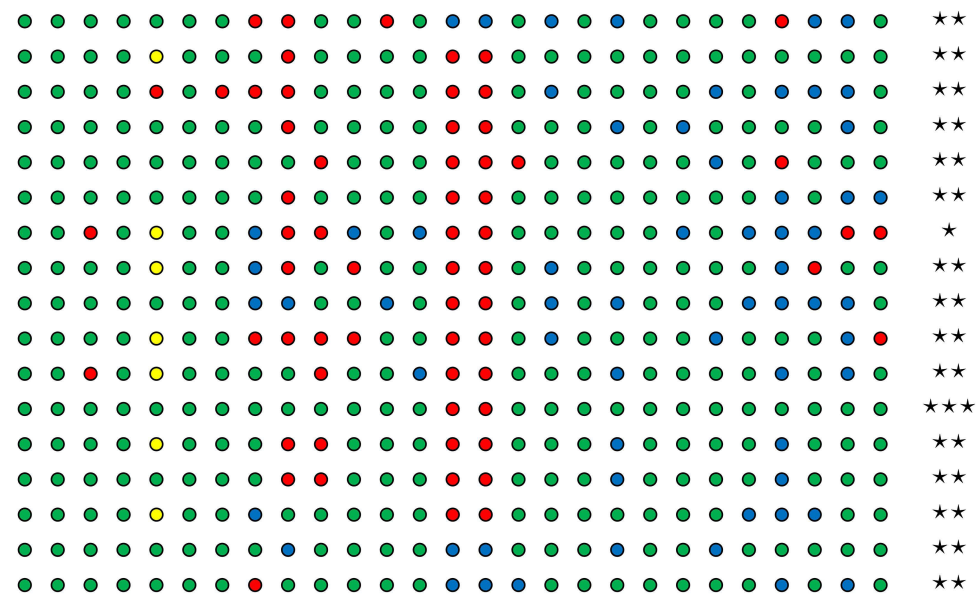

$\bullet=$ Yes,$\circ=$ Partially, $\bullet=$ No, $\bullet=$ Unable to determine,$\bullet=$ Not applicable, $\star=$ Low quality, $\star \star=$ Moderate quality, $\star \star \star=$ High quality

Figure 2 The overall risk of bias for each study (A) cross-sectional design (B) longitudinal design and (C) experimental design

cancellation test, ${ }^{62}$ the 90 min nap condition resulted in greater improvements in attention compared to the $40 \mathrm{~min}$ nap condition.

Daaloul et $\mathrm{al}^{46}$ and Romdhani et $\mathrm{al}^{54}$ examined cognitive performance under sleep restricted conditions of $4.0 \mathrm{~h}$ and $4.5 \mathrm{~h}$ of sleep, respectively. Daaloul et $\mathrm{al}^{46}$ observed improvements in both simple visual reaction time and lower leg reaction time tasks as well as a mental rotation task following a 30 min nap in karate athletes. However, Romdhani et $\mathrm{al}^{54}$ observed improvements in simple reaction time and multiple-choice reaction times following the 20 min nap condition only and not the 90 min nap 
condition. In comparison to the aforementioned studies, Ajjimaporn et $\mathrm{al}^{42}$ examined reaction time using an auditory reaction time task to examine the impact of a $20 \mathrm{~min}$ nap following $3 \mathrm{~h}$ of sleep restriction. The authors observed no differences between the control, sleep restricted and napping conditions. ${ }^{42}$ Finally, Petit et $\mathrm{al}^{52}$ examined the impact on vigilance and attention following a 21 min nap in a $9 \mathrm{~h}$ time in bed condition versus a $5 \mathrm{~h}$ phase advance condition to simulate jet lag. Regardless of the condition, the $21 \mathrm{~min}$ nap improved vigilance and attention performance (Table 2).

In summary, napping improves cognitive performance in the form of visual reaction time, attention and mental rotation tasks. However, no differences were found when reaction time was examined using an auditory reaction time task.

\section{Perceptual Measures of Fatigue and Muscle Soreness, Sleepiness and Alertness}

The positive impact of napping on perceived exertion, subjective fatigue and/or vigour was evident in four of the five studies examining the effects of napping on various perceptual measures. ${ }^{42-44,47,54}$ O'Donnell et $\mathrm{al}^{57}$ demonstrated energy levels remained unchanged in netballers who napped versus those who did not nap. However, it is important to note that O'Donnell et al ${ }^{57}$ employed a 5point Likert scale which may have minimized the variability in responses. ${ }^{63}$ Consistent with the notion of sleep inertia and readiness to perform, Davies et $\mathrm{al}^{47}$ observed that athletes reported greater readiness to perform $2 \mathrm{~h}$ post nap versus $1 \mathrm{~h}$ post-nap. However, there was no comparison between athletes' preparedness or readiness to perform compared to a no nap condition.

Two (5.4\%) studies examined muscle soreness following napping. ${ }^{44,48}$ Driller and Argus ${ }^{48}$ examined the impact of floating in an enclosed, warm, saline-dense water tank for $45 \mathrm{~min}$ as a form of recovery in 60 international level athletes. While a single $45 \mathrm{~min}$ floatation session improved perceived muscle soreness, 27 athletes who napped during the floatation session did not report any differences in their perceived recovery (Table 2). It is possible that in this study, laying in an enclosed, warm, saline-dense water tank had benefits on muscle soreness itself independent of napping. Boukhris et $\mathrm{al}^{44}$ conducted a comprehensive study examining three different napping conditions (no nap, 40 min nap, 90 min nap). The findings related to recovery revealed that napping had a favourable effect on delayed onset muscle soreness ${ }^{64}$ and perceived recovery status. ${ }^{65}$ Further, Boukhris et $\mathrm{al}^{44}$ revealed that the longer nap $(90 \mathrm{~min})$ resulted in decreased delayed onset muscle soreness and increased perceived recovery, indicating that longer naps may have a greater impact on recovery than shorter naps (Table 2).

Four $(10.8 \%)$ studies examined the impact of napping on perceived exertion ${ }^{42,43,54,66}$ using the original Borg scale $^{67}$ or the validated French version ${ }^{68}$ of the Borg scale. All studies revealed napping had a positive impact on perceived exertion such that athletes' rating of perceived exertion was lower following a nap, particularly under sleep restricted conditions. ${ }^{42,43,54,66}$

In summary, evidence supports the role of napping in improving perceptual measures of fatigue and muscle soreness, however not perceived energy levels. Naps have the potential to improve athletes' rating of perceived exertion.

Seven (18.9\%) studies employed a measure of sleepiness and/or alertness (Table 2). The three main scales employed to assess sleepiness were the Epworth Sleepiness Scale $(n=1),{ }^{69}$ the Karolinska Sleepiness Scale $(\mathrm{n}=1)^{70}$ and the Stanford Sleepiness Scale $(\mathrm{n}=$ 2). ${ }^{71}$ In addition, three studies examined alertness using a 100-mm visual analogue scale. ${ }^{45-47}$ All four studies examining sleepiness demonstrated that napping (nap duration range: $20-90 \mathrm{~min}$ ) improved sleepiness (Table 2). ${ }^{43-45,54}$ Although Blanchfield et $\mathrm{al}^{43}$ reported sleep inertia with an initial increase in sleepiness immediately following a 20 min nap, runners' sleepiness scores returned to baseline levels after $90 \mathrm{~min}$.

Similar to sleepiness, two out of three studies reported improved alertness following naps (Table 2). ${ }^{45,46}$ There was variability in the timing of administration of alertness scales with Daaloul et $\mathrm{al}^{46}$ and Davies et $\mathrm{al}^{47}$ administering the scales either immediately or within 15 min upon wakening, whereas Brotherton et $\mathrm{al}^{45}$ administered the scales $3 \mathrm{~h}$ post-nap. Interestingly, out of the three studies examining alertness, Davies et $\mathrm{al}^{47}$ was the only study that did not deprive prior sleep such that participants were not in a sleep-deprived state before napping and subsequently no differences in alertness between the nap and no nap condition were observed.

In summary, napping was found to improve sleepiness and alertness. There was some evidence to indicate sleep inertia; however, this dissipated 90 min post-nap. In circumstances where athletes were well rested, there were no differences for alertness between nap and no nap conditions. 


\section{Psychological State}

Eight (20.6\%) studies examined the psychological impact of napping (Table 2). In these studies, participants were either a) well-rested or b) sleep restricted. In well-rested athletes, Boukhris et $\mathrm{al}^{66}$ revealed that tension, depression, vigour, fatigue and total mood disturbance scores, assessed via the French version of the Profile of Mood State questionnaire, ${ }^{72}$ improved following both a $40 \mathrm{~min}$ and $90 \mathrm{~min}$ nap compared to no nap. However, no differences were observed for confusion. Likewise, Driller and $\operatorname{Argus}^{48}$ revealed positive changes in 5 mood-state variables (ie, worn-out, at-ease, tense, fresh, and exhausted), assessed via the multidimensional mood-state questionnaire, ${ }^{59}$ following a 45 min nap opportunity (mean nap duration: $26 \pm 13 \mathrm{~min}$ ). In contrast, three studies found no differences between napping and no napping conditions on measures of psychological state (eg, Brunel Mood State questionnaire, Profile of Mood State questionnaire and the Short Recovery and Stress Scale) in well-rested athletes. ${ }^{43,45,51}$

Perhaps unsurprisingly, in circumstances where athletes were sleep restricted, napping had a consistent positive impact on mood. ${ }^{45,54}$ In studies where sleep was restricted (3.0-4.5 h per night) ${ }^{45,54}$ napping significantly improved mood as assessed by the Profile of Mood States questionnaire. ${ }^{73}$ Further, Romdhani et $\mathrm{al}^{54}$ showed that longer naps (90 min vs 20 min nap) resulted in greater positive effects on mood. These data are consistent with data in non-athletic populations indicating that in sleepdeprived individuals, napping showed positive effects on mood. $^{74-76}$

In summary, data consistently show that napping results in improved mood states. The improvements in mood following napping were more pronounced following both sleep restriction and longer naps.

\section{Night-Time Sleep}

Two (5.4\%) studies reported the impact of daytime naps on night-time sleep. ${ }^{40,53}$ Thornton et $\mathrm{al}^{40}$ reported that rugby league athletes in their study were encouraged to nap between 15 and $45 \mathrm{~min}$ to avoid any disruptions to their night-time sleep, with nap durations ranging from 30 to $32 \mathrm{~min}$. Athletes that napped during the day went to bed earlier, increased their night-time sleep duration by $30 \mathrm{~min}$ and improved their sleep efficiency by $1 \%$ compared to those who did not nap. In contrast, Petit et al ${ }^{53}$ examined the effects of a 20 min nap scheduled following a normal sleep condition and a $5 \mathrm{~h}$ phase advance condition. The main findings indicated that a $20 \mathrm{~min}$ nap between 13:00 and 14:00 h (normal condition) and between 08:00-09:00 $\mathrm{h}$ (5 $\mathrm{h}$ phase advance condition) increased sleep onset latency but did not alter any other sleep variables, including sleep staging. In the normal sleep condition, sleep onset latency increased from $13 \pm 6$ min to $24 \pm 12$ min. In the $5 \mathrm{~h}$ phase advance condition, sleep onset latency increased from $7 \pm 4$ to $12 \pm 13 \mathrm{~min}$. It is important to acknowledge that these recommendations apply to those athletes with regular circadian timing and may not be appropriate for those with extreme chronotypes.

In summary, there are inconsistent findings regarding the effects of daytime naps on night-time sleep onset latency. Daytime nap durations of up to 45 min may increase the time taken to fall asleep at night in athletes.

\section{Discussion}

This systematic review is the first to explore a) how studies evaluated napping behavior in athletes (frequency, duration, timing and measurement) and $b$ ) how napping impacted physical performance, cognitive performance, perceptual measures (eg, fatigue, muscle soreness, sleepiness and fatigue), psychological state and night-time sleep in athletes. This information is important for athletes and practitioners who provide advice and education to athletes regarding napping.

\section{Why and When Athletes Nap?}

Sleep is essential for optimising recovery and athletic performance. ${ }^{7,77}$ It is well established that athletes' sleep and wake behaviors are dictated by rest days as well as training and competition schedules such that early morning training, multiple training sessions per day ${ }^{5,38}$ and nighttime competition. ${ }^{24}$ Sleep disturbances in response to sportspecific conditions show high inter- and intra-individual variability and athletes may experience insomnia symptoms associated with greater sleep fragmentation indices, longer sleep latencies and excessive daytime sleepiness. In this context, daytime napping represents a common compensatory strategy used by athletes to increase sleep duration over a 24 hour period and potentially counteract daytime sleepiness associated with sleep restriction. ${ }^{78}$ Rest days in athletes may present athletes with opportunities to extend their main night-time sleep duration such that they are less likely to nap on rest days. ${ }^{38}$

This review showed evidence of athletes engaging in two main types of naps a) the prophylactic nap: a nap taken in anticipation of sleep $\operatorname{loss}^{4}$ and b) the replacement nap: a nap taken in response to sleep loss. ${ }^{4}$ No studies specifically identified athletes as engaging in the appetitive 
nap. Although there is no evidence that athletes take naps for convenience or enjoyment, Gupta et $\mathrm{al}^{8}$ applied Harrison and Horne's ${ }^{79}$ idea of "sleepability" such that athletes may have a greater ability to nap on demand without prior sleep debt. Gupta et $\mathrm{al}^{8}$ utilized polysomnography to assess sleep latency associated with a $20 \mathrm{~min}$ nap opportunity taken at 15:00 $\mathrm{h}$ and observed that highperformance athletes showed significantly shorter daytime sleep latencies than non-athletes controls. Further, this difference was maintained even when data were adjusted for pre-trial sleepiness scores and total sleep time. These results suggest that napping may actually reflect the athletes' "sleepability", and that the opportunity to take a nap is not necessarily associated with sleep restriction and daytime sleepiness. Field-based studies in athletes' habitual environment are needed to provide further insight into napping behaviors.

The recuperative value of a nap is dependent on when the nap is taken in regard to the 24 hour circadian rhythm. ${ }^{3}$ For example, the maximum period of daytime circadian sleepiness occurs in the mid-afternoon (13:00-16:00 h) and is often referred to as the post-lunch dip. ${ }^{80}$ Experimental studies conducted in non-athlete populations have indicated that naps taken during this time have a greater recuperative value than naps taken at other times of the day. ${ }^{81-83}$ Despite the established recuperative benefits of napping between 13:00 and 16:00 h, only three studies recorded the timing of naps taken by athletes. ${ }^{25,40,60}$ Interestingly, these studies generally reported athletes napped between 13:00 and 16:00 $\mathrm{h}$ and, similarly, Thornton et $\mathrm{al}^{40}$ observed that only $7 \%$ of naps were taken after 15:00. As noted by Sargent et al ${ }^{38}$ and Lastella et $\mathrm{al}^{84}$ where sleep and wake behaviors were dictated by the timing of training and competition schedules, it is possible that naps were taken between 13:00 and 16:00 $\mathrm{h}$ as a result of the opportunity provided between daily training/competition schedules.

Importantly, no study has investigated the association between athletes' chronotype (the expression of circadian rhythmicity in an individual) and the timing of napping. Chronotype may largely influence sleep behavior, training schedules and the physical or cognitive performance in athletes, with evening-types having delayed sleep onset and offset times and showing peak times for performance later in the day than morning-types. ${ }^{85-87}$ Therefore, the impact of chronotype on napping behavior in athletes warrants further investigation. Regardless of the reasoning for the timing of naps recorded in this review, the optimal time to nap was identified as the maximum period of circadian sleepiness occurring in the mid-afternoon (13:00-16:00 h).

\section{The Impact of Napping}

Overall, the percentage of participants that napped across studies ranged between $11 \%$ and $100 \%{ }^{6,24,31,37,40}$ In the current review, naps not only consistently reduced sleepiness and increased alertness, ${ }^{44-47,54}$ but also produced favourable outcomes on physical and cognitive performance as well perceptual and measures of psychological state (eg, mood) (Table 2). While the evidence to support the benefits of napping in well-rested athletes was clear, ${ }^{42,45,46,49,54}$ the physical, cognitive and mood state benefits of napping were greater in sleep restricted athletes.

Cognitive performance is particularly sensitive to sleep restriction such that cognitive functions are the first level of functioning to become compromised. ${ }^{88,89}$ Upon investigating the studies that examined cognitive performance following napping, it was evident that regardless of participants prior sleep debt, all studies demonstrated a positive influence of napping on cognitive performance. ${ }^{42,44,46,52,54}$ The duration of naps in studies that investigated cognitive performance outcomes ranged from 20 to $90 \mathrm{~min}$, and several domains of cognition were explored (eg, reaction time, mental rotation, psychomotor vigilance, and attention tasks). Of interest the length of the nap likely influences the strength of cognitive performance improvements. For example, Boukhris et $\mathrm{al}^{44}$ observed greater cognitive effects on a digit-cancellation task designed to examine attention with a longer nap (90 min) compared to a shorter nap (20 $\mathrm{min})$.

Overall, napping between 20 and $90 \mathrm{~min}$ improved sleepiness as observed in four studies. ${ }^{43-45,54}$ Blanchfield et $\mathrm{al}^{43}$ did demonstrate initial signs of sleep inertia with a slight increase in sleepiness immediately following a 20 min nap; however, sleepiness returned to baseline levels after $90 \mathrm{~min}$. Similar findings were observed for alertness with two of the three studies demonstrating positive effects for alertness following naps which was thought to be related to the dissipation of sleep homeostatic pressure. ${ }^{45,46}$ In nonathletes, studies have shown that short naps provide a wide range of benefits from increasing alertness to improving cognitive outcomes. ${ }^{76,90}$ Conversely, Davies et $\mathrm{al}^{47}$ did not observe any difference in alertness following a $90 \mathrm{~min}$ daytime nap and a potential explanation for this result was that they did not deprive sleep in runners a priori. 
Regardless of whether athletes were well rested ${ }^{22,66}$ or sleep restricted, ${ }^{45,54}$ napping had a consistent positive impact on measures of psychological state. However, in circumstances where athletes were sleep restricted, napping had a marked positive impact on psychological state. ${ }^{45,54}$ For example, in studies where sleep was restricted (3.0-4.5 h per night), napping significantly improved mood. ${ }^{45,54}$ Further, Romdhani et $\mathrm{al}^{54}$ showed that longer naps (90 min vs $20 \mathrm{~min}$ nap) had greater psychological benefits to mood. These data are consistent with the data on non-athlete populations indicating that napping showed promising effects on psychological state in sleep-deprived individuals. ${ }^{90}$

Based on the findings of the present review, there is minimal evidence to indicate that napping is detrimental for athlete's physical performance. While two studies revealed napping had a negative impact on measures of physical performance, ${ }^{27,56}$ it is important to acknowledge that Knechtle et $\mathrm{al}^{27}$ examined race finish times during a $\sim 24$ hour ultramarathon such that participants napped during the race itself. Suppiah et $\mathrm{al}^{56}$ on the other hand, examined the influence of napping in youth athletes sprint performance under well-rested conditions (ie, $7.8 \mathrm{~h}$ time in bed). While there was a decline in the fastest $20 \mathrm{~m}$ sprint time between nap and no nap conditions, no differences were observed for any other reaction time or sprint performance measures. ${ }^{56}$ Although Suppiah et al ${ }^{56}$ discuss sleep inertia as a plausible explanation for the decline in sprint times, athletes in this study were woken up immediately prior to the onset of Stage 3 sleep (ie, slow wave sleep) to minimize the effects of sleep inertia. Given this was the only negative finding related to physical performance within the study as well as across all studies examined within this review, it is reasonable to conclude that napping does not have a negative impact on physical performance.

\section{Considerations When Implementing Napping for Athletes Sleep Inertia}

Sleep inertia is a transitional state of impaired cognitive performance and reduced alertness upon waking. ${ }^{91}$ Often colloquially described as a feeling of "grogginess", the level of sleep inertia impairment is greatest upon waking and usually takes 15-30 min to fully dissipate. However, some studies in non-athletes have observed performance impairments for up to $2 \mathrm{~h}$ post-wake. ${ }^{92}$ Data derived from non-athlete populations indicate that the duration and/or severity of sleep inertia following a nap can be influenced by a number of factors, including a) prior sleep loss/sleep debt; b) being woken up from slow wave sleep; ${ }^{33}$ c) the amount or percentage of slow-wave sleep in a nap ${ }^{94}$ and d) time of day. ${ }^{95}$ While many studies in the current review suggest that sleep inertia may explain their findings (eg, reductions in physical performance ${ }^{56}$ and alertness ${ }^{43}$ following a nap), no studies to date have specifically investigated the impact of sleep inertia following napping opportunities on measures of performance in athletes.

Given the known impacts of sleep inertia on measures of performance and alertness in non-athletes, athletes should ensure that there is adequate time (at least $30 \mathrm{~min}$ in most cases) for sleep inertia to dissipate following a nap before commencing training or competition. In some cases, it may be possible to accelerate this dissipation by employing known sleep inertia countermeasures, which can be employed proactively (ie, before the nap) or reactively (ie, after a nap). Examples of these countermeasures include caffeine, bright light, sound, temperature and physical activity, and these countermeasures have been reviewed extensively elsewhere. ${ }^{96,97}$ However, it should be noted that none of these strategies can reliably dissipate sleep inertia within the first $15 \mathrm{~min}$ upon waking. ${ }^{96,97}$ Further, if the goal of the napping opportunity is to benefit performance and/or recovery, and there is no immediate need to perform within 30 min of waking, then the impact of sleep inertia is negligible.

A recent study by our team investigated the possibility whether athletes exercising prior to their night-time sleep periods would exhibit greater amounts of slow-wave sleep in their night-time sleep period, which could subsequently impact the severity and/or duration of sleep inertia. ${ }^{98}$ This hypothesis could potentially mean that athletes may be more susceptible to the impacts of sleep inertia given (in most cases) that their level of exercise is greater than the general population. ${ }^{98}$ However, this study concluded that exercise of a moderate-intensity performed $90 \mathrm{~min}$ before bed did not negatively impact sleep inertia and there was no relationship between the amount of slow wave sleep in the preceding sleep period and sleep inertia. ${ }^{98}$ Therefore, it seems unlikely that athletes have a greater likelihood of experiencing enhanced duration and/or severity of sleep inertia compared to non-athletes.

Ensuring a Nap Does Not Impact Night-Time Sleep Napping has the potential to disrupt night-time sleep. This is dependent on several factors including the duration of 
the nap, the timing of the nap and prior sleep debt. In general, the longer the nap, the greater the reduction in sleep propensity; thus, if a nap is taken for a longer period later in the day, and the athlete still attempts to sleep at their habitual time of day, the main night-time sleep period, particularly sleep onset latency, may be disrupted. However, only one study by Petit et $\mathrm{al}^{53}$ showed that sleep onset latency increased the night following a 20 min nap opportunity. As stated previously, the optimal time to nap is when the maximum period of circadian sleepiness occurs in the mid-afternoon (13:00-16:00 h), this timing should also protect delays in sleep onset latency and any intrusion into the night-time sleep period.

\section{Limitations}

The current systematic review has limitations which should be acknowledged. First, articles were only considered for inclusion if they were published in peer-review journals and written in English, resulting in potential language bias. Second, some studies may have reported napping conditions yet failed to indicate if participants had initiated sleep. For example, Brotherton et $\mathrm{al}^{45}$ stated that participants were required to sleep/rest in a quiet room for $60 \mathrm{~min}$ yet, did not provide any data on the number of participants that initiated sleep. Third, articles on napping behavior of Muslim (fasting) athletes during Ramadan and athletes with a disability (eg, Paralympic athletes) were not included in the review. Finally, there is a lack of data reporting nap quality, specifically examining sleep efficiency and/or fragmentation indices (eg, the amount of movement during naps). This is predominantly a reflection of the rapid growth pertaining to sleep in athletes such that main night-time sleep periods have been at the forefront of sleep in athlete research. It is imperative for future studies to provide data examining the napping behaviors of athletes to ensure that sports practitioners and researchers are able to comprehensively examine both quantity and quality of naps in athletes.

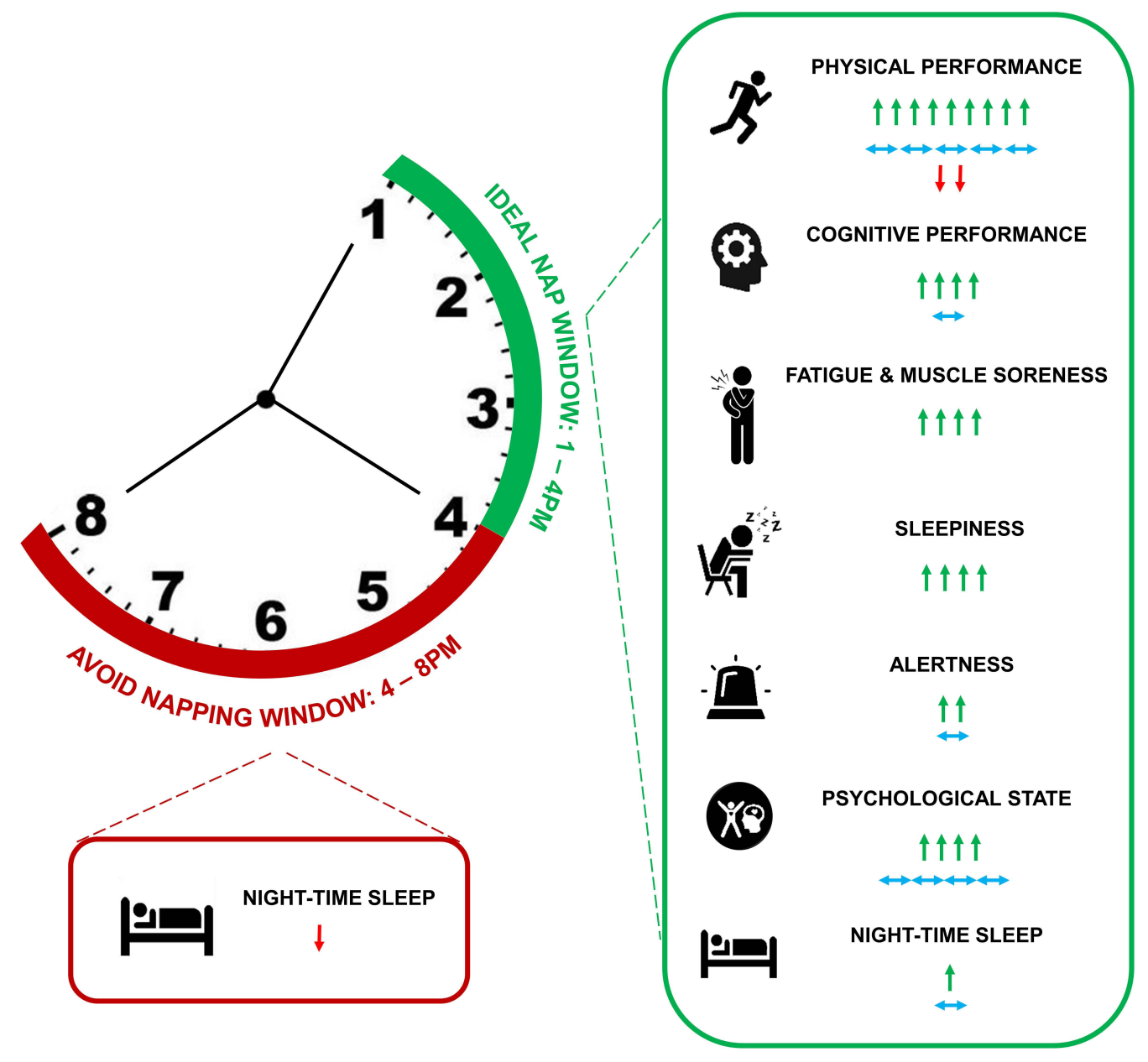

Figure 3 Overview of the evidence examining the impact of napping on various measures of athletic performance. 
Although the overall evidence included in this review was of moderate quality with the majority of experimental or longitudinal studies, it was observed that most of the studies: a) did not include detailed information for nap timing and duration, b) had inconsistencies in reporting of nap frequency, c) focused specifically on the night-time sleep period, and d) relied on self-report data (ie, sleep diaries or questionnaires) to explore napping behavior. Future studies should, therefore, include comprehensive recordings of nap duration and quality, and consider using sleep over a 24 hour period (daytime naps and night-time sleep period), specifically using objective methods of sleep assessment (eg, polysomnography and actigraphy).

\section{Conclusion}

Research investigating napping behaviors indicates that napping is common practice among athletic populations. While napping presents athletes with the opportunity to supplement their night-time sleep, evidence also indicates that napping may be beneficial for a range of measures (eg, physical performance, cognitive performance and mood) in athletes (Figure 3). Data from the present review suggest that athletes should aim to nap for between 20 and 90 min between 13:00 and 16:00 hours. Finally, athletes should allow $30 \mathrm{~min}$ to reduce sleep inertia prior to training or competition to obtain better performance outcomes. Future studies should utilize objective measurement tools to comprehensively evaluate the frequency, duration, timing of naps in athletes and the resulting impact on athletic performance.

\section{Acknowledgments}

The authors would like to extend their appreciation to all researchers that have contributed to the growth of the literature examining the sleep and napping behaviors in athletes.

\section{Disclosure}

The authors report no conflicts of interest or disclosures for this work. This research did not receive funding from any agency.

\section{References}

1. Faraut B, Andrillon T, Vecchierini MF, et al. Napping: a public health issue. From epidemiological to laboratory studies. Sleep Med Rev. 2017;35:85-100. doi:10.1016/j.smrv.2016.09.002
2. Dinges DF. Napping patterns and effects in human adults. In: Dinges DF, Broughton RJ, editors. Sleep and Alertness: Chronobiological, Behavioral and Medical Aspects of Napping. New York: Raven Press; 1989:171-204.

3. Lovato N, Lack L. The effects of napping on cognitive functioning. Prog Brain Res. 2010;185:155-166. doi:10.1016/B978-0-444-537027.00009-9

4. Broughton R, Dinges D. Napping: a ubiquitous enigma. In: Dinges DF, Broughton RJ, editors. Sleep and Alertness: Chronobiological, Behavioral and Medical Aspects of Napping. New York: Raven Press; 1989:1-7.

5. Lastella M, Roach GD, Halson SL, et al. Sleep/wake behaviours of elite athletes from individual and team sports. Eur J Sport Sci. 2015;2 (15):94-100. doi:10.1080/17461391.2014.932016

6. Sargent C, Lastella M, Halson SL, et al. The impact of training schedules on the sleep and fatigue of elite athletes. Chronobiol Int. 2014;31(10):1160-1168. doi:10.3109/07420528.2014.957306

7. Lastella M, Memon AR, Vincent GE. Global research output on sleep research in athletes from 1966 to 2019: a bibliometric analysis. Clocks Sleep. 2020;2(2):99-119. doi:10.3390/clockssleep2020010

8. Gupta L, Morgan K, North C, et al. Napping in high-performance athletes: sleepiness or sleepability? Eur J Sport Sci. 2020;26:1-10. doi:10.1080/17461391.2020.1743765

9. Roberts SSH, Teo W-P, Warmington SA. Effects of training and competition on the sleep of elite athletes: a systematic review and meta-analysis. Br J Sports Med. 2019;53(8):513-522. doi:10.1136/ bjsports-2018-099322

10. Vitale JA, Banfi G, Galbiati A, et al. Effect of a night game on actigraphy-based sleep quality and perceived recovery in top-level volleyball athletes. Int J Sports Physiol Perform. 2019;14(2):265269. doi:10.1123/ijspp.2018-0194

11. Hirshkowitz M, Whiton K, Albert SM, et al. National Sleep Foundation's sleep time duration recommendations: methodology and results summary. Sleep Health. 2015;1:40-43. doi:10.1016/j. sleh.2014.12.010

12. Takahashi M, Arito H. Maintenance of alertness and performance by a brief nap after lunch under prior sleep deficit. Sleep. 2000;23 (6):813-819. doi:10.1037/e361732004-005

13. Tamaki M, Shirota A, Hayashi M, et al. Restorative effects of a short afternoon nap $(<30 \mathrm{~min})$ in the elderly on subjective mood, performance and EEG activity. Sleep Res Online. 2000;3(3):131-139.

14. Tietzel AJ, Lack LC. The recuperative value of brief and ultra-brief naps on alertness and cognitive performance. J Sleep Res. 2002;11 (3):213-218. doi:10.1046/j.1365-2869.2002.00299.x

15. Halson SL. Sleep in elite athletes and nutritional interventions to enhance sleep. Sports Med. 2014;44(Suppl S1):S13-S123. doi:10.1007/s40279-014-0147-0

16. Moher D, Liberati A, Tetzlaff J, et al. Preferred reporting items for systematic reviews and meta-analyses: the PRISMA statement. PLoS Med. 2009;6:e1000097. doi:10.1371/journal.pmed.1000097

17. Munn Z, Stern C, Aromataris E, et al. What kind of systematic review should I conduct? A proposed typology and guidance for systematic reviewers in the medical and health sciences. BMC Med Res Methodol. 2018;18(5). doi:10.1186/s12874-017-0468-4

18. Bergeron MF, Mountjoy M, Armstrong $\mathrm{N}$, et al. International Olympic Committee consensus statement on youth athletic development. Br J Sports Med. 2015;49(13):843-851. doi:10.1136/bjsports2015-094962

19. McKinney J, Velghe J, Fee J, et al. Defining athletes and exercisers. Am J Cardiol. 2019;123(3):532-535. doi:10.1016/j.amjcard.2018.11.001

20. Swann C, Moran A, Piggott D. Defining elite athletes: issues in the study of expert performance in sport psychology. Psychol Sport Exerc. 2015;16:3-14. doi:10.1016/j.psychsport.2014.07.004

21. Dinges DF, Orne MT, Whitehouse WG, et al. Temporal placement of a nap for alertness: contributions of circadian phase and prior wakefulness. Sleep. 1987;10(4):313-329. doi:10.1093/sleep/10.4.313 
22. Downs SH, Black N. The feasibility of creating a checklist for the assessment of the methodological quality both of randomised and non-randomised studies of health care interventions. J Epidemiol Community Health. 1998;52(6):377-384. doi:10.1136/jech.52.6.377

23. Bonnar D, Bartel K, Kakoschke N, et al. Sleep interventions designed to improve athletic performance and recovery: a systematic review of current approaches. Sports Med. 2018;48(3):683-703. doi:10.1007/ s40279-017-0832-x

24. Fullagar H, Skorski S, Duffield R, et al. The effect of an acute sleep hygiene strategy following a late-night soccer match on recovery of players. Chronobiol Int. 2016;33(5):490-505. doi:10.3109/ 07420528.2016

25. Fullagar HH, Duffield R, Skorski S, et al. Sleep, travel, and recovery responses of national footballers during and after long-haul international air travel. Int J Sports Physiol Perform. 2016;11(1):86-95. doi:10.1123/ijspp.2015-0012

26. Fullagar HH, Skorski S, Duffield R, et al. Impaired sleep and recovery after night matches in elite football players. J Sports Sci. 2016;34 (14):1333-1339. doi:10.1080/02640414.2015.1135249

27. Knechtle B, Wirth A, Knechtle P, et al. No improvement in race performance by naps in male ultra-endurance cyclists in a $600-\mathrm{km}$ ultra-cycling race. Chin J Physiol. 2012;55(2):125-133. doi:10.4077/ CJP.2012.BAA022

28. Poussel M, Laroppe J, Hurdiel R, et al. Sleep management strategy and performance in an extreme mountain ultra-marathon. Res Sports Med. 2015;23:330-336. doi:10.1080/15438627.2015.1040916

29. Venter RE, Potgieter JR, Barnard JG. The use of recovery modalities by elite South African team athletes. South African J Res Sport, Phy Edu Recreation. 2010;32(1):133-145. doi:10.4314/sajrs.v32i1.54106

30. Martin T, Arnal PJ, Hoffman MD, et al. Sleep habits and strategies of ultramarathon runners. PLoS One. 2018;13(5):e0194705. doi:10.1371/journal.pone. 0194705

31. Caia J, Scott TJ, Halson SL, et al. Do players and staff sleep more during the pre- or competitive season of elite rugby league? Eur $J$ Sport Sci. 2017;17(8):964-972. doi:10.1080/17461391.2017.1335348

32. Carter JR, Gervais BM, Adomeit JL, et al. Subjective and objective sleep differ in male and female collegiate athletes. Sleep Health. 2020;6(5):623-628. doi:10.1016/j.sleh.2020.01.016

33. Hurdiel R, Riedy SM, Millet GP, et al. Cognitive performance and self-reported sleepiness are modulated by time-of-day during a mountain ultramarathon. Res Sports Med. 2018;26(4):482-489. doi:10.1080/15438627.2018.1492401

34. Jones MJ, Dawson B, Gucciardi DF, et al. Evening electronic device use and sleep patterns in athletes. J Sports Sci. 2019;37:864-870. doi:10.1080/02640414.2018.1531499

35. Kölling S, Wiewelhove T, Raeder C, et al. Sleep monitoring of a sixday microcycle in strength and high-intensity training. Eur J Sport Sci. 2016;16(5):507-515. doi:10.1080/17461391.2015.1041062

36. Mah CD, Kezirian EJ, Marcello BM, et al. Poor sleep quality and insufficient sleep of a collegiate student-athlete population. Sleep Health. 2018;4(3):251-257. doi:10.1016/j.sleh.2018.02.005

37. Romyn G, Robey E, Dimmock JA, et al. Sleep, anxiety and electronic device use by athletes in the training and competition environments. Eur J Sport Sci. 2016;16(3):301-308. doi:10.1080/ 17461391.2015.1023221

38. Sargent C, Halson S, Roach G. Sleep or swim? Early-morning training severely restricts the amount of sleep obtained by elite swimmers. Eur J Sport Sci. 2014;14(Suppl 1):S310-S315. doi:10.1080/ 17461391.2012 .696711

39. Stevens CJ, Thornton HR, Fowler PM, et al. Long-haul northeast travel disrupts sleep and induces perceived fatigue in endurance athletes. Front Physiol. 2018;9:1826. doi:10.3389/fphys.2018.01826

40. Thornton HR, Duthie GM, Pitchford NW, et al. Effects of a 2-week high-intensity training camp on sleep activity of professional rugby league athletes. Int J Sports Physiol Perform. 2017;12(7):928-933. doi:10.1123/ijspp.2016-0414
41. Walsh JA, Sanders D, Hamilton DL, et al. Sleep profiles of elite swimmers during different training phases. $J$ Strength Cond Res. 2019;33(3):811-818. doi:10.1519/jsc.0000000000002866

42. Ajjimaporn A, Ramyarangsi P, Siripornpanich V. Effects of a 20-min nap after sleep deprivation on brain activity and soccer performance. Int J Sports Med. 2020;41(14):1009-1016. doi:10.1055/a-1192-6187

43. Blanchfield AW, Lewis-Jones TM, Wignall JR, et al. The influence of an afternoon nap on the endurance performance of trained runners. Eur J Sport Sci. 2018;18(9):1177-1184. doi:10.1080/ 17461391.2018.1477180

44. Boukhris O, Trabelsi K, Ammar A, et al. A 90 min daytime nap opportunity is better than 40 min for cognitive and physical performance. Int $J$ Environ Res Public Health. 2020;17(13):4650. doi:10.3390/ijerph17134650

45. Brotherton EJ, Moseley SE, Langan-Evans C, et al. Effects of two nights partial sleep deprivation on an evening submaximal weightlifting performance; are $1 \mathrm{~h}$ powernaps useful on the day of competition? Chronobiol Int. 2019;36(3):407-426. doi:10.1080/ 07420528.2018.1552702

46. Daaloul H, Souissi N, Davenne D. Effects of napping on alertness, cognitive, and physical outcomes of karate athletes. Med Sci Sports Exerc. 2019;51(2):338-345. doi:10.1249/MSS.0000000000001786

47. Davies DJ, Graham KS, Chow CM. The effect of prior endurance training on nap sleep patterns. Int J Sports Physiol Perform. 2010;5 (1):87-97. doi:10.1123/ijspp.5.1.87

48. Driller MW, Argus CK. Flotation restricted environmental stimulation therapy and napping on mood state and muscle soreness in elite athletes: a novel recovery strategy? Perform Enhanc Health. 2016;5 (2):60-65. doi:10.1016/j.peh.2016.08.002

49. Hammouda O, Romdhani M, Chaabouni Y, et al. Diurnal napping after partial sleep deprivation affected hematological and biochemical responses during repeated sprint. Biol Rhythm Res. 2018;49(6):927939. doi:10.1080/09291016.2018.1429553

50. Pelka M, Ferrauti A, Meyer T, et al. How does a short, interrupted recovery break affect performance and how is it assessed? A study on acute effects. Int J Sports Physiol Perform. 2017;12:S114-S1121. doi:10.1123/ijspp.2016-0399

51. Pelka M, Kölling S, Ferrauti A, et al. Acute effects of psychological relaxation techniques between two physical tasks. J Sports Sci. 2017;35(3):216-223. doi:10.1080/02640414.2016.1161208

52. Petit E, Bourdin H, Tio G, et al. Effects of a 20-min nap post normal and jet lag conditions on P300 components in athletes. Int $J$ Sports Med. 2018;39:508-516. doi:10.1055/a-0599-0888

53. Petit E, Mougin F, Bourdin H, et al. A 20-min nap in athletes changes subsequent sleep architecture but does not alter physical performances after normal sleep or 5-h phase-advance conditions. Eur $J$ Appl Physiol. 2014;114:305-315. doi:10.1007/s00421-013-2776-7

54. Romdhani M, Souissi N, Chaabouni Y, et al. Improved physical performance and decreased muscular and oxidative damage with postlunch napping after partial sleep deprivation in athletes. Int $J$ Sports Physiol Perform. 2020;15(6):874-883. doi:10.1123/ ijspp.2019-0308

55. Romyn G, Lastella M, Miller DJ, et al. Daytime naps can be used to supplement night-time sleep in athletes. Chronobiol Int. 2018;35 (6):865-868. doi:10.1080/07420528.2018.1466795

56. Suppiah HT, Low CY, Choong G, et al. Effects of a short daytime nap on shooting and sprint performance in high-level adolescent athletes. Int J Sports Physiol Perform. 2018;14(1):76-82. doi:10.1123/ ijspp.2018-0107

57. O'Donnell S, Beaven CM, Driller M. The influence of match-day napping in elite female netball athletes. Int $J$ Sports Physiol Perform. 2018;13(9):1143-1148. doi:10.1123/ijspp.2017-0793

58. Thornton HR, Delaney JA, Duthie GM, et al. Effects of preseason training on the sleep characteristics of professional rugby league players. Int $J$ Sports Physiol Perform. 2018;13(2):176-182. doi:10.1123/ijspp.2017-0119 
59. Steyer R, Schwenkmezger P, Notz P, et al. Testtheoretische analysen des mehrdimensionalen befindlichkeitsfragebogens (MDBF) [In German: theoretical analysis of a multidimensional mood questionnaire (MDBF)]. Diagnostica. 1994;40(4):320-328.

60. Kölling S, Duffield R, Erlacher D, et al. Sleep-related issues for recovery and performance in athletes. Int J Sports Physiol Perform. 2019;14(2):144-148. doi:10.1123/ijspp.2017-0746

61. Draper N, Whyte G. Here's a new running based test of anaerobic performance for which you need only a stopwatch and a calculator Peak Performance. 1997;96:3-5.

62. Hatta T, Yoshizaki K, Ito Y, et al. Reliability and validity of the digit cancellation test, a brief screen of attention. Psychologia. 2012;55:246-256. doi:10.2117/psysoc.2012.246

63. Baron H. Strengths and limitations of ipsative measurement. J Occup Organ Psychol. 1996;69:49-56. doi:10.1111/j.2044-8325.1996.tb00599.x

64. Dierking JK, Bemben MG, Bemben DA, et al. Validity of diagnostic ultrasound as a measure of delayed onset muscle soreness. J Orthop Sports Phys Ther. 2000;30(3):116-125. doi:10.2519/ jospt.2000.30.3.116

65. Laurent CM, Green JM, Bishop PA, et al. A practical approach to monitoring recovery: development of a perceived recovery status scale. J Strength Cond Res. 2011;25(3):620-628. doi:10.1519/ JSC.0b013e3181c69ec6

66. Boukhris O, Abdessalem R, Ammar A, et al. Nap opportunity during the daytime affects performance and perceived exertion in $5-\mathrm{m}$ shuttle run test. Front Physiol. 2019;10:779. doi:10.3389/ fphys.2019.00779

67. Borg G. Psychophysical scaling with applications in physical work and the perception of exertion. Scand $J$ Work Environ Health. 1990;16(Suppl 1):S55-S58. doi:10.5271/sjweh.1815

68. Haddad M, Chaouachi A, Castagna C, et al. Validity and psychometric evaluation of the French version of RPE scale in young fit males when monitoring training loads. Sci Sports. 2013;28(2):e29e35. doi:10.1016/j.scispo.2012.07.008

69. Johns MW. A new method for measuring daytime sleepiness: the Epworth Sleepiness Scale. Sleep. 1991;14(6):540-545. doi:10.1093/ sleep/14.6.540

70. Santhi N, Groeger JA, Archer SN, et al. Morning sleep inertia in alertness and performance: effect of cognitive domain and white light conditions. PLoS One. 2013;8(11):e79688. doi:10.1371/journal. pone. 0079688

71. Hoddes E, Zarcone V, Smythe H, et al. Quantification of sleepiness: a new approach. Psychophysiology. 1973;10(4):431-436. doi:10.1111/ j.1469-8986.1973.tb00801.x

72. Cayrou S, Dickès P, Dolbeault S. Version française du profile of mood states (POMS-f) [In French: French version of the Profile Of Mood States (POMS-f)]. $J$ de Thérapie Comportementale et Cognitive. 2003;13(2):83-88.

73. McNair DM, Droppleman LF. Manual for the Profile of Mood States. San Diego, CA: Educational and Industrial Testing Service; 1971.

74. Tietzel AJ, Lack LC. The short-term benefits of brief and long naps following nocturnal sleep restriction. Sleep. 2001;24(3):293-300. doi:10.1093/sleep/24.3.293

75. Liu J, Feng R, Ji X, et al. Midday napping in children: associations between nap frequency and duration across cognitive, positive psychological well-being, behavioral, and metabolic health outcomes. Sleep. 2019;42(9):zsz126. doi:10.1093/sleep/zsz126

76. Hayashi M, Watanabe M, Hori T. The effects of a 20 min nap in the mid-afternoon on mood, performance and EEG activity. Clin Neurophysiol. 1999;110(2):272-279. doi:10.1016/s1388-2457(98) 00003-0

77. Halson S. Nutrition, sleep and recovery. Eur J Sport Sci. 2008;8 (2):119-126. doi:10.1080/17461390801954794

78. Lastella M, Roach GD, Miller DJ, et al. Athletes underestimate sleep quantity during daytime nap opportunities. Chronobiol Int. 2018;35:869-871. doi:10.1080/07420528.2018.1466787
79. Harrison Y, Horne J. "High sleepability without sleepiness". The ability to fall asleep rapidly without other signs of sleepiness. Neurophysiol Clin. 1996;26:15-20. doi:10.1016/0987-7053(96)81530-9

80. Folkard S, Akerstedt T. A three process model of the regulation of alertness and sleepiness. In: Ogilvie R, Broughton R, editors. Sleep, Arousal, and Performance: Problems and Promises. Boston: Birkhiiuser; 1991:11-26.

81. Lack L, Lushington $\mathrm{K}$. The rhythms of human sleep propensity and core body temperature. J Sleep Res. 1996;5:1-11. doi:10.1046/ j.1365-2869.1996.00005.x

82. Naitoh P, Angus RG. Napping and human functioning during prolonged work. In: Dinges DF, Broughton RJ, editors. Sleep and Alertness: Chronobiological, Behavioral and Medical Aspects of Napping. New York: Raven Press; 1989:221-246.

83. Taub J, Hawkins D. Van de Castle R. Temporal relationships of napping behavior to performance, mood states and sleep physiology. Sleep Res. 1978;7:164.

84. Lastella M, Roach GD, Halson SL, et al. Sleep/wake behaviour of endurance cyclists before and during competition. J Sports Sci. 2015;33(3):293-299. doi:10.1080/02640414.2014.942690

85. Vitale JA, Weydahl A. Chronotype, physical activity, and sport performance: a systematic review. Sports Med. 2017;47(9):1859-1868. doi:10.1007/s40279-017-0741-z

86. Lastella M, Roach GD, Halson SL, et al. The chronotype of elite athletes. J Hum Kinet. 2016;54:219-225. doi:10.1515/hukin-2016-0049

87. Vitale JA, Bonato M, Galasso L, et al. Sleep quality and high intensity interval training at two different times of day: a crossover study on the influence of the chronotype in male collegiate soccer players. Chronobiol Int. 2017;34(2):260-268. doi:10.1080/ 07420528.2016.1256301

88. Belenky G, Wesensten NJ, Thorne DR, et al. Patterns of performance degradation and restoration during sleep restriction and subsequent recovery: a sleep dose-response study. J Sleep Res. 2003;12:1-12. doi:10.1046/j.1365-2869.2003.00337.x

89. Van Dongen HPA, Maislin G, Mullington JM, et al. The cumulative cost of additional wakefulness: dose-response effects on neurobehavioral functions and sleep physiology from chronic sleep restriction and total sleep deprivation. Sleep. 2003;26(2):117-126. doi:10.1093/sleep/26.2.117

90. Milner CE, Cote KA. Benefits of napping in healthy adults: impact of nap length, time of day, age, and experience with napping. $J$ Sleep Res. 2009;18(2):272-281. doi:10.1111/j.1365-2869.2008.00718.x

91. Trotti LM. Waking up is the hardest thing I do all day: sleep inertia and sleep drunkenness. Sleep Med Rev. 2017;35:76-84. doi:10.1016/ j.smrv.2016.08.005

92. Jewett ME, Wyatt JK, Ritz-de Cecco A, et al. Time course of sleep inertia dissipation in human performance and alertness. $J$ Sleep Res. 1999;8(1):1-8. doi:10.1111/j.1365-2869.1999.00128.x

93. Tassi P, Bonnefond A, Engasser O, et al. EEG spectral power and cognitive performance during sleep inertia: the effect of normal sleep duration and partial sleep deprivation. Physiol Behav. 2006;87 (1):177-184. doi:10.1016/j.physbeh.2005.09.017

94. Matchock RL, Mordkoff JT. Effects of sleep stage and sleep episode length on the alerting, orienting, and conflict components of attention. Exp Brain Res. 2014;232:811-820. doi:10.1007/s00221-013-3790-z

95. Groeger JA, Lo JC, Burns CG, et al. Effects of sleep inertia after daytime naps vary with executive load and time of day. Behav Neurosci. 2011;125(2):252-260. doi:10.1037/a0022692

96. Kovac K, Ferguson SA, Paterson JL, et al. Exercising caution upon waking-can exercise reduce sleep inertia? Front Physiol. 2020;11:254. doi:10.3389/fphys.2020.00254

97. Dawson D, Ferguson SA, Vincent GE. Safety implications of fatigue and sleep inertia for emergency services personnel. Sleep Med Rev. 2020;55:101386. doi:10.1016/j.smrv.2020.101386

98. Vincent GE, Sargent C, Roach GD, et al. Exercise before bed does not impact sleep inertia in young healthy males. J Sleep Res. 2020;29 (3):e12903. doi:10.1111/jsr.12903 


\section{Publish your work in this journal}

Nature and Science of Sleep is an international, peer-reviewed, open access journal covering all aspects of sleep science and sleep medicine, including the neurophysiology and functions of sleep, the genetics of sleep, sleep and society, biological rhythms, dreaming, sleep disorders and therapy, and strategies to optimize healthy sleep.

Submit your manuscript here: https://www.dovepress.com/nature-and-science-of-sleep-journ
The manuscript management system is completely online and includes a very quick and fair peer-review system, which is all easy to use. Visit http://www.dovepress.com/testimonials.php to read real quotes from published authors. 